\title{
Evidence-based Nursing Practice in New York State: A Delphi Study
}

Jennifer A. Klimek Yingling ${ }^{1 *}$, Darlene M. Del Prato ${ }^{2}$, Priscilla S. Worrall ${ }^{3}$, Rona F. Levin ${ }^{1}$, Victoria L. Record ${ }^{1,5} \&$ Deborah Elliot $^{4}$

\author{
${ }^{1}$ Utica College, NY, USA \\ ${ }^{2}$ SUNY Polytechnic Institute, NY, USA \\ ${ }^{3}$ Pace University, NY, USA and Upstate Medical University College of Nursing, NY, USA \\ ${ }^{4}$ Center for Nursing Foundation of New York State Nurses, NY, USA \\ ${ }^{5}$ Rochester Regional Health \\ *Corresponding Author: Jennifer A. Klimek Yingling, Utica College, NY, USA. Email: jaklimek@utica.edu \\ DOI: https://dx.doi.org/10.47988/janany.70647868.1.1
}

\begin{abstract}
Background. Today's landscape of population health, economics, and educational delivery methods have influenced the progress and implementation of nursing practice built on the best evidence. International literature has documented barriers to implementing and sustaining evidence-based practice (EBP).

Purpose. The purposes of this study were to (a) identify barriers to implementing evidence into clinical practice in New York State (NYS), (b) prioritize resources needed to address these barriers, and (c) determine how the Cathryne A. Welch Center for Nursing (CNR) of the Foundation of NYS Nurses might provide support to address the identified barriers.

Methodology. Using a modified Delphi technique, a sample of nurse leaders completed two online survey rounds. The first Round provided qualitative feedback, which was categorized via content analysis, with a second Round that asked respondents to rank the categories from Round I.

Results. Organizational culture, productivity demands, and time were ranked as the top three barriers to implementing EBP in NYS. Time, leader support, and guidance/mentoring were identified as top resources needed to employ EBP. Respondents reported the CNR could facilitate EBP through financial support, communication, and mentoring. Data stratification revealed differences between rural and urban respondents, academic and clinical respondents, and geographical regions of the State, and differences in resources and support needed.
\end{abstract}

Conclusion. Findings confirm barriers for NYS nurses mirror those described in the literature. Resources and support needed, however, may be demographically specific. Awareness of these differences will enable the CNR to best support NYS nurses' implementation of EBP across the State.

MeSH Keywords: Nursing, Delphi Technique, Evidence-Based Practice, Barriers to EBP, Resources for EBP

Funding: The authors did not receive any funding from the public, commercial, or not-for-profit sectors.

Conflict of Interest: The authors declare no actual or potential conflict of interest. 


\section{Evidence-based Nursing Practice in New York State: A Delphi Study}

Over the last two decades, a challenging landscape of population health, healthcare economics, and educational delivery has influenced the progress and continued implementation of sound nursing practice built on best evidence. Evidence-based practice (EBP) is a problem-solving approach to patient care that embodies the best evidence coupled with clinicians' knowledge, patient evaluations, and practice data with patient preference to drive decision making (Melnyk \& Fineout-Overholt, 2015; Melnyk et al., 2012). Evidence implementation is an essential aspect of contemporary nursing practice. Institutions with effective structures for finding and implementing quality evidence demonstrate improved patient outcomes (Levin et al., 2016; Melnyk et al., 2017; Ryan-Madonna et al., 2020), reduced costs (Melnyk et al., 2016), and greater nursing satisfaction (Kim et al., 2017). Despite these documented benefits, there are barriers to implementing and sustaining EBP (Hasanpoor et al., 2019; Klimek Yingling, 2020; Melnyk et al., 2020; Warren et al., 2016).

Frequently cited barriers of EBP include a lack of resources (e.g., personnel, time, and library search availability), low engagement, and lack of enthusiasm (Dogherty et al., 2013). These obstacles are likely to remain if nursing leaders are not actively involved in creating realistic solutions. Historically, the Foundation of New York State Nurses Cathryne A. Welch Center for Nursing Research (CNR) has helped nurses promote EBP. The CNR identified the need to assess current barriers and needs as essential to promoting evidence-based practice. Fostering evidence-based nursing practice includes identifying and mitigating potential and tangible obstacles to best practice. Little research has been conducted on the barriers specific to NYS nurses.

Discussion with the CNR Steering Committee, representation from the Foundation Board of Directors, and ANA-NY Executive Director led to the strategic approach to collect more data on NYS clinical agencies' needs to move evidence-based practices forward. Therefore, the purposes of this study were to identify current barriers to implementing evidence into clinical practice in New York State, prioritize the resources needed to address these barriers, and determine ways that the Foundation of New York State Nurses' CNR can provide support to address identified barriers.

\section{Literature Review}

Nurses play a critical role in the quality of healthcare provided (Smiley et al., 2018). EBP is recognized as an essential aspect of contemporary professional nursing practice that fosters highquality patient care. Compared to care grounded in tradition, EBP improves healthcare quality and safety and promotes improved patient outcomes, including lower morbidity and mortality and higher patient satisfaction (Melnyk \& Fineout-Overholt, 2015; Melnyk et al., 2016). In addition, EBP lowers healthcare costs and fosters health care providers' professional satisfaction (Välimäki et al., 2018).

Despite significant benefits and the plethora of evidence available to inform and improve patient care, research indicates that EBP is not implemented consistently by health care professionals, including direct care nurses and nurse leaders (Harding et al., 2014; Melnyk et al., 2016; Melnyk et al., 2020; Warren et al., 2016; ). Previous research over the last two decades, across practice settings in the United States and internationally, revealed multiple interrelated barriers to EBP, including: a) lack of EBP knowledge and competencies, b) lack of EBP mentors, c) organizational cultures and work environments that do not support EBP, d) demanding patient assignments, e) inadequate time and resources to search for and evaluate evidence, f) lack of expectations and organizational mandates to implement evidence-based care, g) volume of new knowledge disseminated in professional journals, $h$ ) pressure to maintain the status quo, and i) leader/manager resistance (Duncombe, 2018; Harding et al., 2014; Melnyk \& Fineout-Overholt, 2015; Melnyk et al., 2012; Melnyk et al., 2016; Melnyk et al., 2020). Conversely, features that foster EBP include: a) beliefs that EBP improves patient care and outcomes, b) EBP knowledge and skills, c) education in research methods, d) expert support and mentoring, e) a supportive culture including those from interdisciplinary colleagues, f) evidencebased organizational policies and protocols, and g) leaders and managers who support and role model EBP (Bianchi et al., 2018; Duncombe, 2018; Melnyk et al., 2012; Melnyk et al., 2016).

Bianchi et al. (2018) postulated that clinicians' implementation of EBP depends on a supportive organizational culture led by leaders and managers who encourage and role model EBP. However, Melnyk et al. (2016) revealed that while nurse leaders expressed positive beliefs about EBP, their application of EBP in their organizations was often low. Nursing leaders have been called upon to transform contemporary healthcare practices and systems to make healthcare decisions based on the best available evidence (Melnyk et al., 2020).

Clinicians' perspectives about key facilitators of EBP include EBP knowledge and skills, support from interdisciplinary colleagues, and support from leaders and managers who role model EBP. Previous research also advanced nursing knowledge about the persistence of multiple barriers to EBP. Few studies, however, focused on chief nursing officers' and other clinical leaders' perspectives regarding barriers to implementing EBP or resources needed to mitigate existing barriers and establish EBP within healthcare systems. Additionally, there is scant qualitative work focusing on nurse leaders' perspectives on barriers and resources regarding EBP. This study addresses this gap in the current literature regarding nurse leaders' perspectives in NYS and the resources they view as necessary to implement evidencebased practices in their organizations.

\section{Design}

\section{Method}

A modified Delphi technique (McPherson et al., 2018) was used to gain consensus from a purposive sample of nurse leaders on barriers to implementing EBP in clinical settings, resources needed to address those barriers, and ways that the CNR might provide support. The Delphi technique is an adaptable research 
method used to reach consensus among a group of experts through repetitive rounds of two to three surveys (Hasson et al., 2000; McPherson et al., 2018). Round I of the survey used open-ended questions to obtain participants' perspectives about the research questions. After the initial results were obtained, the research team analyzed the data and identified categories. In Round II, participants were asked to rank categories based on their views and priorities in achieving EBP in clinical settings. Participants were provided with a list of categories with exemplar statements that explained the categories' meaning based on the Round I participants' responses. This will be further delineated in the results.

\section{Sample}

Purposive sampling was conducted from a target population of registered professional nurses in NYS with self-identified expertise in EBP and responsibility for leading or facilitating change in clinical practice arenas. Additionally, participant eligibility requirements included a minimum of an earned bachelor's or graduate degree in nursing, or a bachelor's degree in nursing and a graduate degree in a relevant field, e.g., administration, informatics. The target goal was fifty participants with broad geographical representation, rural and urban/suburban, and position distribution across NYS.

Participants included clinical practice leaders, Magnet/ Pathway to Excellence coordinators, nurse administrators, nurse consultants, and faculty members responsible for teaching EBP courses and mentoring students' EBP/quality improvement projects at all nursing education levels. Settings included: tertiary care, managed care, home care, ambulatory care, assisted living, long-term care, hospice, palliative care, and community care organizations. Participants were recruited through co-investigator professional networks and relationships. Letters describing the study purpose and expected time commitment for participation were sent electronically to potential participants.

\section{Ethical Considerations}

The Institutional Review Board at Utica College approved the study. All participants were over 18 years of age, with no exclusions based on age, gender, race, ethnicity, or sexual preference. Coinvestigators conducting analysis did not have access to Round I participants' identifiable information and deleted any identifiable information from Round II data before analysis began. To ensure participants' confidentiality, at least four participants had to be included in a sub-group to analyze demographic break-outs. No funding was obtained for this study. No compensation was provided to the participants at any stage of the research.

\section{Data Collection}

Data were collected electronically using Cvent survey software (www.cvent.com, McClean, VA, USA). Cvent is a survey and feedback management platform designed to enable organizations to connect with members through email surveys. Participants were invited to participate in the survey by email with a link that captured data directly in Cvent. Reminder emails were sent directly from Cvent to all participants for both rounds, with two reminder emails sent for each Round. Initially, for Round I, four weeks were allotted to collect data after the survey was launched. Unfortunately, this timeframe coincided with the peak of the COVID-19 pandemic in NYS. Due to the severity of the pandemic and the significant role of nursing during this time, an additional four weeks were added for data collection.

In Round I, participants were asked to provide demographic data and provide short-answer narrative responses to the following questions:

1. What do you perceive as the three major barriers to implementing evidence into practice in your clinical agency?

2. What do you believe are the three most important resources needed to escalate the implementation of evidence into clinical practice?

3. How do you believe the Foundation of NYS Nurses Cathryne A. Welch Center for Nursing Research can help support efforts to implement evidence into practice?

As described below, Round I data were analyzed to develop categories with exemplar quotes to be sent to participants for ranking in Round II.

For Round II, final categories with exemplar quotes from Round I were sent to participants by email with a link to the Cvent database. Participants were instructed to rank each category's importance, with one being most important for addressing the question at the participant's agency or institution. Participants were again asked to provide demographic information. Additionally, those who responded in Round I were asked whether they thought their responses were adequately reflected in Round II categories.

\section{Data Analysis Procedures}

For each Round, survey responses were downloaded into Excel spreadsheets and forwarded to co-investigators conducting the analysis. Descriptive content analysis of Round I open-text narrative responses was conducted to synthesize participant statements into categories of like responses. Each category identified a central theme reflecting individual statements. The data were independently analyzed in teams of two initially for each question. Four co-investigators discussed and analyzed the data until consensus was reached.

For analysis of Round II data, co-investigators first looked at responses to the question asking whether participants thought categories from Round I data accurately and adequately reflected their narrative responses. Investigators then analyzed the ranking of categories for each question using medians and modes to determine aggregate ranks for the total sample as well as for participants grouped by demographic categories for the primary role (clinical or academic), location of setting (rural or urban/ suburban), and geographic region of NYS (downstate, northeast, central, or western). Round II data were analyzed with descriptive statistics. For each question, a summary ranking of categories was determined first by looking at median scores, second by looking at the number of participants who scored that category as one of the top three, and lastly by looking at the number of participants who scored that category as among the two or three least important. Given the small sample size and consensus among participants after Round II, investigators determined that a third-round was not needed. 


\section{Results}

In Round I, of 88 surveys sent, 24 surveys were returned for an initial $27 \%$ response rate. Three surveys were eliminated, two from non-RNs, and one from a nurse who stated no involvement in EBP, leaving a usable response rate of $22 \%$. Among the 21 participants whose responses were included in Round I analysis, 11 provided complete responses, 18 responded to one or more questions about clinical barriers, and 14 responded to questions about resources needed and ways the CNR could support EBP. In Round II, 17 participants responded out of 69, yielding a 25\% response rate. Four of the 17 participants did not participate in Round I; however, their responses were included in the analysis.

In Round I, the nurse leaders were asked how they influence EBP in their practice. This question was a select all-that-apply item. The nurse leaders $(n=18)$ reported that they: Guide nurses to integrate EBP in their clinical role (14), Guide nursing students to integrate EBP in their clinical role (10), Collect evidence to inform EBP (9), and Lead integration of EBP in an agency (8). The majority of nurse leaders who completed Round II ( $\mathrm{n}=17$ [70.6\%]) reported a doctoral level nursing degree as their highest attained degree. Three participants $(17.6 \%)$ reported a masterslevel as their highest nursing degree. Two participants (11.8\%) reported a doctoral-level degree in a field other than nursing as their attained highest degree. The majority of participants in Round II reported their primary roles as CNO in agency or institution $(\mathrm{n}=17$ [29\%]), Conducts/guides EBP projects or research in a practice setting (18\%), and EBP educator for clinical RNs or RN students (41\%). The practice locations in Round II were reported as urban/ suburban downstate, urban/suburban central, rural central, urban/ suburban northeast, rural northeast, and urban/suburban western. No participants indicated they were from rural downstate and rural western NY in Round II. Demographics for participants of Round I and Round II are displayed in Table 1.
Table 1

Participants' Demographics for Rounds I and II

\begin{tabular}{|c|c|c|c|}
\hline \multicolumn{2}{|c|}{ Demographic category } & \multirow{2}{*}{\begin{tabular}{|l|l|}
$\begin{array}{l}\text { Round I } \\
(\mathrm{n}=18)\end{array}$ \\
-- \\
\end{tabular}} & \multirow{2}{*}{\begin{tabular}{|l} 
Round \\
II \\
$(\mathrm{n}=\mathbf{1 7})$ \\
-- \\
\end{tabular}} \\
\hline Highest & Baccalaureate & & \\
\hline earned & Masters & 3 & 3 \\
\hline $\begin{array}{l}\text { nursing } \\
\text { degree }\end{array}$ & Doctorate & 15 & $12^{\mathrm{b}}$ \\
\hline \multirow{6}{*}{$\begin{array}{l}\text { Primary role } \\
\text { (select all } \\
\text { that apply) }{ }^{\text {a }}\end{array}$} & $\begin{array}{l}\text { CNO in agency or } \\
\text { institution }\end{array}$ & 3 & 5 \\
\hline & $\begin{array}{l}\text { Completed EBP project } \\
\text { in grad school }\end{array}$ & 1 & 1 \\
\hline & $\begin{array}{l}\text { Conducts/guides EBP } \\
\text { projects or research in a } \\
\text { practice setting }\end{array}$ & 5 & 3 \\
\hline & $\begin{array}{l}\text { EBP educator for } \\
\text { clinical RNs or RN } \\
\text { students }\end{array}$ & 5 & 7 \\
\hline & $\begin{array}{l}\text { Clinically based EBP } \\
\text { leader }\end{array}$ & -- & 1 \\
\hline & $\begin{array}{l}\text { Other: Round I: } \\
\text { research, DON, acad. } \\
\text { CAN; Round II: vice } \\
\text { dean, provost }\end{array}$ & 4 & 2 \\
\hline \multirow{5}{*}{$\begin{array}{l}\text { How you } \\
\text { impact EBP } \\
\text { in your } \\
\text { practice } \\
\text { (select all } \\
\text { that apply) } \\
\text { [this asked } \\
\text { only in } \\
\text { Round I] }\end{array}$} & $\begin{array}{l}\text { Lead integration of EBP } \\
\text { in an agency }\end{array}$ & 8 & -- \\
\hline & $\begin{array}{l}\text { Guide nurses to } \\
\text { integrate EBP in their } \\
\text { clinical role }\end{array}$ & 14 & -- \\
\hline & $\begin{array}{l}\text { Guide nursing students } \\
\text { to integrate EBP in their } \\
\text { clinical role }\end{array}$ & 10 & -- \\
\hline & $\begin{array}{l}\text { Collect evidence to } \\
\text { inform EBP }\end{array}$ & 9 & -- \\
\hline & $\begin{array}{l}\text { Oher: support, RCA } \\
\text { process }\end{array}$ & 2 & -- \\
\hline \multirow{8}{*}{$\begin{array}{l}\text { Practice } \\
\text { location in } \\
\text { NYS }\end{array}$} & $\begin{array}{l}\text { Urban/suburban } \\
\text { downstate }\end{array}$ & 1 & 4 \\
\hline & Rural downstate & -- & -- \\
\hline & Urban/suburban central & 4 & $4^{c}$ \\
\hline & Rural central & 1 & 2 \\
\hline & $\begin{array}{l}\text { Urban/suburban } \\
\text { northeast }\end{array}$ & 7 & 3 \\
\hline & Rural northeast & 1 & 2 \\
\hline & Urban/suburban western & 3 & 2 \\
\hline & Rural western & 1 & -- \\
\hline
\end{tabular}

${ }^{\text {a }}$ Each participant chose only one response in Round I; one chose three in Round II.

${ }^{\mathrm{b}}$ one participant chose two locations; 1st recorded;

${ }^{c}$ two additional participants chose doctorate in another field 
A descriptive content analysis of barriers evaluated opentext narrative responses from Round I revealed eight categories describing roadblocks to implement EBP (Table 2). The top barriers were time to implement EBP, practicing nurses' lack of knowledge about EBP, professional role formation, organizational culture/environment, academic preparation of students/graduate nurses, productivity demands, competing paradigms, and resources.

Table 2

Top Clinical Barriers to Implementing EBP

\begin{tabular}{|c|c|}
\hline Categories & Supporting Quotes \\
\hline $\begin{array}{l}\text { Time to } \\
\text { implement } \\
\text { EBP }\end{array}$ & $\begin{array}{l}\text { - The actual time to implement evidence- } \\
\text { based new practices. } \\
\text { - Frontline staff having dedicated time for } \\
\text { EBP at the clinical bedside }\end{array}$ \\
\hline $\begin{array}{l}\text { Practicing } \\
\text { nurses' lack } \\
\text { of knowledge } \\
\text { about EBP }\end{array}$ & $\begin{array}{l}\text { - Knowledge and understanding of how } \\
\text { EBP strengthens practice } \\
\text { - Access and skill in critiquing the } \\
\text { evidence, i.e., research-based articles, } \\
\text { manuscripts, reports } \\
\text { - Lack of understanding of the impact of } \\
\text { not using EBP }\end{array}$ \\
\hline $\begin{array}{l}\text { Professional } \\
\text { Role } \\
\text { Formation }\end{array}$ & $\begin{array}{l}\text { - Staff engagement, failure to see the } \\
\text { connection to practice } \\
\text { - Influencing clinical nurses to be open to } \\
\text { changes in practice based on evidence. } \\
\text { - Making nurses aware of their autonomy } \\
\text { and ability to institute evidence-based } \\
\text { practice techniques } \\
\text { - Nurses feeling competent to initiate and } \\
\text { champion change in practice along with }\end{array}$ \\
\hline
\end{tabular}

\begin{tabular}{|c|c|}
\hline $\begin{array}{l}\text { Organizational } \\
\text { Culture/ } \\
\text { Environment }\end{array}$ & $\begin{array}{l}\text { - Resistance to change } \\
\text { - Lack of buy-in from nursing staff } \\
\text { - Availability of resources to support } \\
\text { evidence for best practices } \\
\text { - Leaders supporting and empowering } \\
\text { clinical nurses to lead change }\end{array}$ \\
\hline $\begin{array}{l}\text { Academic } \\
\text { Preparation } \\
\text { Students/ } \\
\text { Graduate } \\
\text { Nurses }\end{array}$ & $\begin{array}{l}\text { - The lack of emphasis of EBP in the } \\
\text { educational preparation of new nurses; } \\
\text { specifically, integration into every course } \\
\text { throughout the curriculum } \\
\text { - At the associate level, there is a lack } \\
\text { of time in the curriculum to devote to } \\
\text { developing EBP and research skills. }\end{array}$ \\
\hline $\begin{array}{l}\text { Productivity } \\
\text { Demands }\end{array}$ & $\begin{array}{l}\text { - Productivity demands on nurses } \\
\text { - Dedicated time and resources for the } \\
\text { actual implementation of the EBP } \\
\text { change. } \\
\text { - The clinical practice setting is so busy } \\
\text { caring for patients that the clinicians do } \\
\text { not engage in thinking outside of their } \\
\text { "normal" practices. }\end{array}$ \\
\hline
\end{tabular}

\begin{tabular}{|l|l|}
\hline Competing & $\begin{array}{l}\text { Lack of awareness of its role amongst } \\
\text { Paradigms }\end{array}$ \\
& $\begin{array}{l}\text { Ther nursing leaders and front line staff } \\
\text { If the implementation will increase } \\
\text { expense, there can be resistance } \\
\text { - Inconsistent support from leadership to } \\
\text { embrace EBP...do not walk the talk nor } \\
\text { talk the walk }\end{array}$ \\
\hline Resources & $\begin{array}{l}\text { Availability of resources to support } \\
\text { evidence for best practices } \\
\text { Time, organization's allocation of } \\
\end{array}$ \\
& resources \\
\hline
\end{tabular}

The analysis identified nine categories from participants' responses to resource needs (Table 3). The three most important resources for implementing EBP were time, point of care expertise, and skilled guidance/mentors.

Table 3

Three most important resources for implementing EBP

\begin{tabular}{|c|c|}
\hline $\begin{array}{l}\text { Key Concept/ } \\
\text { Word }\end{array}$ & Supporting Quotes \\
\hline Time & $\begin{array}{l}\text { - Dedicated time for staff to engage in } \\
\text { EBP/Research activities } \\
\text { - Facilitating the time for nurses to } \\
\text { seek new evidence }\end{array}$ \\
\hline $\begin{array}{l}\text { Point of care } \\
\text { (POC) expertise }\end{array}$ & $\begin{array}{l}\text { - Engagement in changing practices } \\
\text { from the front line } \\
\text { - Place mentors in key areas or service } \\
\text { lines to support point of care EBP } \\
\text { integration } \\
\text { - NURSE SCIENTIST on site }\end{array}$ \\
\hline $\begin{array}{l}\text { Skilled guidance/ } \\
\text { mentors - } \\
\text { academic \& } \\
\text { clinical }\end{array}$ & $\begin{array}{l}\text { - EBP mentors for academics and new } \\
\text { nurses } \\
\text { - Tight college and clinical site } \\
\text { integrations } \\
\text { - Skilled guidance into interpreting and } \\
\text { critiquing research }\end{array}$ \\
\hline $\begin{array}{l}\text { Organizational } \\
\text { support/structure }\end{array}$ & $\begin{array}{l}\text { - Financial business case for EBP } \\
\text { - Time provided by employers for } \\
\text { research and writing } \\
\text { value of best evidence via awards, } \\
\text { rounds, presentations, etc. } \\
\text { - Providing structures for nurses to } \\
\text { explore evidence \& change practice } \\
\text { - Need for appropriate staffing } \\
\text { levels to allow time for education } \\
\text { and thoughtful application of best } \\
\text { practices }\end{array}$ \\
\hline
\end{tabular}




\begin{tabular}{|c|c|}
\hline $\begin{array}{l}\text { Evidence/ } \\
\text { resources - } \\
\text { accessible, } \\
\text { relevant, robust }\end{array}$ & $\begin{array}{l}\text { - Ease of access (able to be } \\
\text { - } \text { Townloaded on cellphones } \\
\text { they juried/vetted) } \\
\text { - Making statistics clinically } \\
\text { - meaningful } \\
\text { - Access to research } \\
\text { - Robust databases \& library resources } \\
\text { - Rich library resources with easy access }\end{array}$ \\
\hline $\begin{array}{l}\text { Common } \\
\text { language }\end{array}$ & $\begin{array}{l}\text { - Standardized educational tools } \\
\text { - } \quad \text { EBP Model } \\
\text { - Need for a common language, i.e., } \\
\text { staff nurses don't recognize QSEN }\end{array}$ \\
\hline Leader support & $\begin{array}{l}\text { - Leadership setting the example } \\
\text { through use of credible evidence in } \\
\text { practice-regardless of specialty- } \\
\text { and engaging faculty, staff, and other } \\
\text { leaders in EBP projects } \\
\text { - Leaders that support EBP and } \\
\text { empower nurses to share ideas and be } \\
\text { creative }\end{array}$ \\
\hline Teams & $\begin{array}{l}\text { - Cohesive team and resources to } \\
\text { develop/integrate EBP practice } \\
\text { - Research teams }\end{array}$ \\
\hline $\begin{array}{l}\text { Knowledge/ } \\
\text { competence }\end{array}$ & $\begin{array}{l}\text { - Nurses at ALL levels of practice } \\
\text { need to be fully immersed and be } \\
\text { knowledgeable of EBP processes } \\
\text { - Competence interpreting/critiquing } \\
\text { research findings }\end{array}$ \\
\hline
\end{tabular}

Lastly, five categories emerged from the analysis of responses to suggest how the CNR could support EBP implementations in participants' agencies (Table 4). These were financial support/ grants and scholarships, communication/visibility/dissemination, getting buy-in, educational tools/resources, and mentoring.

\section{Table 4}

Top Three Ways the CNR Can Help You Implement EBP

\begin{tabular}{|l|l|}
\hline $\begin{array}{l}\text { Key Concept/ } \\
\text { Word }\end{array}$ & Supporting Quotes \\
\hline $\begin{array}{l}\text { Financial } \\
\text { support/grants/ } \\
\text { scholarships }\end{array}$ & $\begin{array}{l}\text { Support nursing research through } \\
\text { scholarships }\end{array}$ \\
& - Grants for faculty \\
& - Grants to support pilot projects \\
\hline
\end{tabular}

\begin{tabular}{|c|c|}
\hline $\begin{array}{l}\text { Communication/ } \\
\text { visibility/ } \\
\text { dissemination }\end{array}$ & $\begin{array}{l}\text { - ..venues for sharing research } \\
\text { outcomes etc. } \\
\text { - Greater visibility/connection at all } \\
\text { levels of nursing practice } \\
\text { - Make your resources more well-known } \\
\text { (PR) } \\
\text { - Give nurses and student nurses an } \\
\text { avenue to broadcast their evidence- } \\
\text { based strategies } \\
\text { - Awards } \\
\text { - Encourage dissemination of nursing } \\
\text { research } \\
\text { - Provide a venue for educators and } \\
\text { service folks to come together to close } \\
\text { the EBP application gap...this requires } \\
\text { knowing how to manage change in real } \\
\text { point-of-care situations }\end{array}$ \\
\hline Getting buy-in & $\begin{array}{l}\text { - Education to Sr Team members of the } \\
\text { value investing in such education will } \\
\text { improve patient outcomes and reduce } \\
\text { mortality } \\
\text { - Giving them the "what's in it for me" }\end{array}$ \\
\hline $\begin{array}{l}\text { Education: tools } \\
\text { \& resources }\end{array}$ & $\begin{array}{l}\text { - Provide educational opportunities for } \\
\text { RNs to develop EBP skills, especially } \\
\text { for the AD-level RNs } \\
\text { - Increase the ease of access (ability to } \\
\text { access during class or clinical) } \\
\text { - Programs to support EBP that are } \\
\text { accessible and affordable } \\
\text { - Repository of EBP tools } \\
\text { - Offering a toolkit for each stage of the } \\
\text { process to assist users } \\
\text { - Offering short webinars to educate or } \\
\text { remind nurses ho to perform EBP- } \\
\text { relate to toolkits }\end{array}$ \\
\hline Mentoring & $\begin{array}{l}\text { - Support from experts in the field to } \\
\text { local hospitals } \\
\text { - Resource pooling/mentoring-perhaps } \\
\text { one-on-one guidance } \\
\text { - Set up a mentor network with clinical } \\
\text { research skilled specialists } \\
\text { - Publication support }\end{array}$ \\
\hline
\end{tabular}

All 17 participants responding in Round II completed the ranking of all categories from Round I. (Please note that all rankings, regardless of the number of categories, considered "one" as most important.) Participants who indicated they also had responded in Round I noted that the categories accurately and adequately reflected their earlier input. Two participants, however, commented that they were not certain or could not recall. Given the relatively small number of categories for each question, participants were asked to rank all categories rather than ranking only their top three. Round II ranking results were multi-modal, and medians were used in some cases. Rural versus urban/suburban and geographical location demographics were separated, so data could be aggregated to include at least four 
participants in a sub-group. Because Western NYS only had two participants, those data are not displayed in the tables. However, data from participants from Western NYS were included in the total rankings and non-geographic specific break-outs. Table 5 identifies the eight barriers to EBP which emerged from Round I with exemplars and their rank order. Participants ranked the top three categories: organizational culture/environment, productivity demands, and time to implement EBP.

Table 5

Round II Ranking of Clinical Barriers to Implementing EBP by Participants in Total and by Demographic Sub-group

\begin{tabular}{|c|c|c|c|c|c|c|c|c|}
\hline $\begin{array}{l}\text { Barriers to } \\
\text { implement EBP }\end{array}$ & $\begin{array}{l}\text { Time to } \\
\text { implement } \\
\text { EBP }\end{array}$ & $\begin{array}{l}\text { Practicing } \\
\text { RNs' } \\
\text { lack of } \\
\text { knowledge } \\
\text { about EBP }\end{array}$ & $\begin{array}{l}\text { Professional } \\
\text { role } \\
\text { formation }\end{array}$ & $\begin{array}{l}\text { Org. culture/ } \\
\text { environment }\end{array}$ & $\begin{array}{l}\text { Academic } \\
\text { prep of } \\
\text { students/ } \\
\text { graduate } \\
\text { RNs }\end{array}$ & $\begin{array}{l}\text { Productivity } \\
\text { demands }\end{array}$ & $\begin{array}{l}\text { Competing } \\
\text { paradigms }\end{array}$ & Resources \\
\hline Total $n=17$ & 3 & 5 & 8 & 1 & 7 & 2 & 6 & 4 \\
\hline Rural (n=4) & 4 & 5 & 8 & 1 & 3 & 2 & 7 & 6 \\
\hline $\begin{array}{l}\text { Urban/ } \\
\text { Suburban } \\
(n=13)\end{array}$ & 3 & 5 & 8 & 1 & 7 & 2 & 6 & 4 \\
\hline Clinical $(n=8)$ & 4 & 5 & 8 & 2 & 7 & 1 & 6 & 3 \\
\hline $\begin{array}{l}\text { Academic } \\
(\mathrm{n}=9)\end{array}$ & 3 & 4 & 8 & 1 & 7 & 2 & 6 & 5 \\
\hline Central $(n=6)$ & 3 & 5 & 7 & 1 & 6 & 4 & 8 & 2 \\
\hline $\begin{array}{l}\text { Northeast } \\
(\mathrm{n}=5)\end{array}$ & 3 & 4 & 8 & 2 & 7 & 1 & 5 & 6 \\
\hline $\begin{array}{l}\text { Downstate } \\
(n=4)\end{array}$ & 2 & 6 & 8 & 1 & 7 & 3 & 5 & 4 \\
\hline
\end{tabular}

Note: categories ranked with $1=$ most important

Participants also ranked the nine categories identified as resources needed to implement EBP. Table 6 presents these results by the total number of participants and by demographic sub-group. The top three resources needed were time, leader support, and skilled guidance/mentors.

Table 6

Round II Ranking of Resources Needed to Implement EBP by Participants in Total and by Demographic Sub-group

\begin{tabular}{|l|l|l|l|l|l|l|l|l|l|}
\hline $\begin{array}{l}\text { Resources needed to } \\
\text { implement EBP }\end{array}$ & Time & $\begin{array}{l}\text { Point } \\
\text { of care } \\
\text { expertise }\end{array}$ & $\begin{array}{l}\text { Skilled } \\
\text { guidance/ } \\
\text { mentors } \\
\text { (academic } \\
\text { /clinical) }\end{array}$ & $\begin{array}{l}\text { Org. } \\
\text { support// } \\
\text { structure }\end{array}$ & $\begin{array}{l}\text { Evidence/ } \\
\text { resources } \\
\text { accessible, } \\
\text { relevant, } \\
\text { robust }\end{array}$ & $\begin{array}{l}\text { Common } \\
\text { language }\end{array}$ & $\begin{array}{l}\text { Leader } \\
\text { support }\end{array}$ & Teams & $\begin{array}{l}\text { Knowledge/ } \\
\text { competence }\end{array}$ \\
\hline Total n=17 & 1 & 6 & 3 & 4 & 7 & 9 & 2 & 8 & 5 \\
\hline & & & & & & & & & \\
\hline Rural (n=4) & 3 & 4 & 2 & 6 & 8 & 9 & 1 & 7 & 5 \\
\hline Urban/Suburban $(\mathbf{n = 1 3})$ & 1 & 7 & 4 & 2 & 6 & 9 & 3 & 8 & 5 \\
\hline & & & & & & & & & \\
\hline Clinical (n=8) & 1 & 6 & 3 & 4 & 7 & 9 & 2 & 8 & 5 \\
\hline Academic (n=9) & 4 & 7 & 1 & 2 & 5 & 9 & 3 & 8 & 6 \\
\hline Central (n=6) & 1 & 6 & 3 & 5 & 7 & 9 & 2 & 8 & 4 \\
\hline Northeast (n=5) & 1 & 6 & 3 & 4 & 8 & 9 & 2 & 7 & 5 \\
\hline Downstate (n=4) & 2 & 8 & 4 & 1 & 5 & 9 & 3 & 7 & 6 \\
\hline
\end{tabular}

Note: categories ranked with $1=$ most important 
Finally, participants ranked the nine categories identified as assistance from the CNR (see Table 7) in the following order of importance: 1. Financial support/grants/scholarships, 2. Communication/visibility/dissemination, 3. Mentoring, 4. Educational tools and resources, and 5. Getting buy-in.

Table 7

Round II Ranking of Ways the CNR can Support EBP Implementation by Participants in Total and by Demographic Sub-group

\begin{tabular}{|l|l|l|l|l|l|}
\hline $\begin{array}{l}\text { Support from } \\
\text { CNR }\end{array}$ & $\begin{array}{l}\text { Financial support/ } \\
\text { grants/ scholarships }\end{array}$ & $\begin{array}{l}\text { Communication/ } \\
\text { visibility/ dissemination }\end{array}$ & $\begin{array}{l}\text { Getting buy- } \\
\text { in }\end{array}$ & $\begin{array}{l}\text { Education: tools \& } \\
\text { resources }\end{array}$ & Mentoring \\
\hline Total n=17 & 1 & 2 & 5 & 4 & 3 \\
\hline & & 5 & 3 & 2 & 1 \\
\hline Rural (n=4) & 4 & & & & \\
\hline Urban/Suburban & & 1 & 5 & 3 & 4 \\
\hline$(\mathbf{n = 1 3})$ & 2 & & & & \\
\hline & & 2 & 5 & 3 & 4 \\
\hline Clinical $(\mathbf{n}=\mathbf{8})$ & 1 & 3 & 4 & 5 & 1 \\
\hline Academic (n=9) & 2 & & & & \\
\hline & & 4 & 5 & 3 & 1 \\
\hline Central (n=6) & 2 & 4 & 5 & 2 & 3 \\
\hline Northeast $(\mathbf{n}=\mathbf{5})$ & 1 & 1 & 3 & 4 & 5 \\
\hline Downstate (n=4) & 2 & & & \\
\hline
\end{tabular}

Note: categories ranked with $1=$ most important

\section{Discussion}

The purpose of a Delphi survey is to reach a consensus among a group of experts about a research question. In this study, the findings represent the consensus of an expert panel of nurse leaders regarding the barriers to implementing EBP in clinical practice in New York State (NYS), the resources needed to overcome these barriers, and how the CNR might provide support to address identified barriers.

\section{Barriers}

In our sample, organizational culture and environment, productivity demands, and time ranked as the top three barriers to implementing EBP. Barriers reflected in the category of "organizational culture and environment" included resistance to change, lack of buy-in from nursing staff, resource availability to support evidence for best practices, and leaders supporting and empowering clinical nurses to lead change. Previous research also reported cultures and workplace environments that did not support EBP (Dalheim et al., 2012; Harding et al., 2014; Heydari et al., 2014; Melnyk et al., 2016; Wilson et al., 2015).

Participants identified organizational culture and environment as the first barrier to EBP. Not surprisingly, they also reported leader support as an essential resource to implement EBP. This finding is consistent with previous literature that underscored nursing leadership's influence on EBP (Bianchi et al., 2018; Hasanpoor et al., 2019). Transforming the workplace culture so that nurses' clinical practice is consistently grounded in evidence is a complex undertaking. Nurse leaders play a critical role in transforming the workplace culture to embrace EBP by orienting, educating, and mentoring new clinicians, providing education and mentoring for seasoned clinicians, and allocating necessary resources, including time (Bianchi et al., 2018; Melnyk et al., 2016). Consistent with previous literature, this study identified time as a crucial resource for implementing EBP (Crable et al., 2020; Pittman et al., 2018; Sidani et al., 2016). Barends et al. (2017) reported that lack of time was perceived as the most significant barrier to applying EBP in management. Crable et al. (2020) reported that practicing nurses identified time, limited knowledge, and resistance to change as barriers to practice EBP.

The study also reported productivity demands one of the top barriers to implementing EBP. The findings by Camargo et al. (2018) also identified a lack of knowledge for evidence evaluation, work overload, and resistance to change of practice as barriers. Work overload is multifaceted and may encompass productivity demands, time, leadership support, and organizational environment. Beyond nursing, Harding et al. (2014) found that allied health clinicians and managers viewed healthcare's rapid pace and maintaining patient flow as a higher priority than EBP. Harding et al. also found lack of time to be correlated with workload reported barriers to EBP: attitudes and expectations, resources, and lack of understanding of EBP.

\section{Resources}

Participants reported time, leader support, and "guidance and mentoring" as the top three resources needed to implement EBP. The barriers to EBP, and the resources needed to implement EBP, were inversely related to one another in several instances. For example, while time was reported as a significant resource, lack of time was also viewed as a top barrier to EBP. This finding is consistent with previous research (Alatawi et al., 2020; Melnyk et al., 2012; Renolen et al., 2018). Nurses need time to locate, 
critically appraise, and implement evidence in practice (Melnyk \& Fineeout-Overholt, 2015).

Participants also reported that leadership support was a critical resource to employ EBP and often drives decision-making in organizations. Managers and organizations have a unique position to promote an organizational environment that fosters appreciation and application of good evidence to decision making (Barends et al., 2017; Bianchi et al., 2018; Melnyk et al., 2016; Pittman et al., 2018). Leadership support has consistently been identified in the literature as essential to promote and sustain EBP. Melnyk et al. (2016) reported that organizational leaders hold EBP in high regard but have a low personal implementation of EBP; they report EBP was not a priority in their organization's fiscal budgets, are not clear about the steps of EBP, and lack the confidence to implement EBP properly.

Barends et al. (2017) reported that leaders believe EBP is relevant. However, when faced with problem-solving, they often look to personal experience, knowledge from formal education, and intuition rather than scientific evidence. Pittman et al. (2018) also postulated that "leaders" actions positively influence change and excellence in practice and create a supportive work culture. A focus on mentoring the mentor from an academic setting into practice may help promote the use of EBP by organizational leadership for decision making. Fostering EBP competency across the nursing trajectory may create a culture of EBP needed to improve healthcare quality.

\section{Demographic variation}

As addressed above, participants' consensus mirrored much of what the literature described. Closer examination of rank scores stratified by demographics revealed that participants' geographic location, work setting, and primary role were associated with differences that would not have been evident if only panel-level data had been examined. The most significant and most frequent differences in rank scores were found between rural settings and urban or suburban areas.

Academic preparation of students and graduate nurses was seen as the 3rd most important barrier to implementing EBP in rural settings. In contrast, academic preparation was ranked 7 th, second from the bottom, by participants in urban or suburban settings. Given this difference in ranking of barriers, it is not surprising that rural participants ranked organizational structure and support as only 6th of 9 resources needed, while urban and suburban participants ranked organizational structure and support as the 2nd most crucial resource needed. Rural participants identified leader support and skilled guidance, and mentoring as their most needed resources (1st and 2nd, respectively). These differences were seen again in rank scores for how the CNR could help support the implementation of EBP, with rural participants ranking mentoring from the CNR as most important compared with a ranking second from the bottom (4th of 5 categories) by urban and suburban participants. Similar differences in ranks given to organizational structure and support and mentoring were found between participants in central and northeastern regions compared with those in downstate and western regions; however, these most likely were associated with more rural participants in central and northeast parts of NYS.
Differences in the ranking of resources needed for EBP and ways the CNR could support EBP implementation were also found between participants primarily in clinical roles compared with those primarily in academic roles. Both groups, however, scored productivity demands among their top two barriers to EBP implementation. For clinicians, time was the most important resource needed, whereas academically based participants ranked time as 4 th of 9 categories. Academically based participants ranked mentoring as the most important way the CNR could support EBP implementation, whereas clinicians ranked mentoring as 4 th of 5 possible categories.

\section{Recommendations for the CNR}

Respondents reported the CNR could facilitate EBP through financial support, "communication, visibility and dissemination," and mentoring. When examined by geographic regions, it was interesting that rural geographic regions sought mentoring, whereas urban and suburban areas sought communication, visibility, and dissemination. This finding may represent that rural areas have challenges different from their urban counterparts in exposure to clinical nurse specialists and graduate prepared nurses. Perhaps using current technology, the CNR may increase communication, visibility, and dissemination throughout NYS. The use of technology may also provide mentoring to a broader area where nurses do not have access to nursing leaders who are well versed in EBP.

\section{Limitations of the Present Study}

There are several limitations of this study. First, the low response rate and resulting small sample were most likely a consequence of launching the survey simultaneously with the first spread of COVID-19 across NYS. Second, unequal representation across regions limits the CNR's ability to identify the needs of all regions throughout NYS. Third, although every attempt was made to provide clear instructions for study participants, one conceptual issue arose throughout the final Delphi round regarding whether participants reviewed the exemplars to define each ranking item before ranking their selections. Lastly, some respondents did not participate in both rounds.

\section{Conclusions and Future Prospects}

This study's findings mirror those described in the literature examining primary barriers to implementing EBP in clinical settings. While resources and support are needed, they may be demographically specific. Awareness of these differences will enable the CNR to best support NYS nurses' implementation of EBP across the State in various demographic regions. The Delphi survey findings propose a preliminary list of resources and support needed that may contribute to increasing the implementation of EBP into clinical practice in NYS. As stated in the introduction, one of the main reasons the CNR decided to undertake this study was that findings would give direction to its strategic planning. Results indicated the three top-ranked ways that the CNR could help, i.e., through financial support, increasing "communication, visibility, and dissemination" of EBP, and mentoring, differing by geographic region and clinical or academic affiliation. The authors have already begun working on communication and 
dissemination by writing this article and submitting abstracts to two well-known nursing organizations for possible presentation. The next steps are to explore ways to address the other support that is needed to enhance EBP in NYS.

As always, the more information that is available, the better the ability to decide how to move forward. Additional knowledge about nursing leaders' needs and abilities regarding their own EBP knowledge may be a key to better understanding how to support them. Also, a better understanding of the diverse needs of nursing leaders by geographic regions is needed. This study highlights the importance of collaboration between geographic regions, healthcare organizations, and leadership organizations within the State of New York to achieve our mutual goals for providing the best healthcare to all NYS citizens.

Acknowledgment: The authors wish to acknowledge the leadership and support of the New York State Foundation for Nursing, Cathryne A. Welch Center for Nursing Research, for creating the impetus for this study and bringing together nursing colleagues from across New York State to participate as authors, counselors, and participants in this work. We also wish to acknowledge the support, counsel, and continued involvement of ANA-NY. Last but not least, we wish to acknowledge each other for the collegiality and collaboration we have experienced in completing this study and this manuscript.

\section{References}

Alatawi, M., Aljuhani, E., Alsufiany, F., Aleid, K., Rawah, R., Aljanabi, S., \& Banakhar, M. (2020). Barriers of implementing evidence-based practice in nursing profession: A literature review. American Journal of Nursing Science, 9(1), 35-42. https://dx.doi.org/10.11648/j.ajns.20200901.16

Barends, E., Villanueva, J., Rousseau, D. M., Briner, R. B., Jepsen, D. M., Houghton, E., \& ten Have, S. (2017). Managerial attitudes and perceived barriers regarding evidence-based practice: An international survey. PLoS ONE, 12(10), 1-15. https://dx.doi.org/10.1371/journal.pone.0184594

Bianchi, M., Bagnasco, A., Bressan, V., Barisone, M., Timmins, F., Rossi, S., Pellegrini, R., Aleo, G., \& Sasso, L. (2018). A review of the role of nurse leadership in promoting and sustaining evidence-based practice. Journal of Nursing Management, 26(8), 918 - 932. https://dx.doi.org/10.1111/jonm.12638

Camargo, F. C., Iwamoto, H., Galvão, C., Pereira, G., Andrade, R., \& Masso, G. (2018). Competences and barriers for the evidence-based practice in nursing: An integrative review. Revista Brasileira de Enfermagem, 71(4), 2030-2038. https:// dx.doi.org/10.1590/0034-7167-2016-0617

Crable, J., Highfield, M., \& Patmon, F. (2020). Evidence-based practice knowledge, attitudes, practices, and barriers. Nursing Critical Care, 15(5), 24-32. https://dx.doi.org/10.1097/01. ccn.0000694076.73284.a3

Dalheim, A., Harthug, S., Nilsen, R. M., \& Nortvedt, M. W. (2012). Factors influencing the development of evidence-based practice among nurses: A self-report survey. BMC Health
Services Research, 12, 367. https://dx.doi.org/10.1186/14726963-12-367

Dogherty, E. J., Harrison, M. B., Graham, I. D., Vandyk, A. D., \& Keeping-Burke, L. (2013). Turning knowledge into action at the point-of-care: The collective experience of nurses facilitating the implementation of evidence-based practice. Worldviews on Evidence-Based Nursing, 10(3), 129-139. https://dx.doi.org/10.1111/wvn.12009

Duncombe, D.C. (2018). A multi-institutional study of the perceived barriers and facilitators to implementing evidencebased practice. Journal of Clinical Nursing, 27, 1216-1226. https://dx.dx.doi.org/10.1097\%2FMD.0000000000017209

Harding, K., Porter, J., Horne-Thompson, A., Donley, E., \& Taylor, N.F. (2014). Not enough time or a low priority? Barriers to evidence-based practice for allied health clinicians. Journal of Continuing Education in Nursing, 34(4), 224-.231. https:// dx.doi.org/10.1002/chp.21255

Hasanpoor, E., Siraneh Belete, Y., Janati, A., Hajebrahimi, S., \& Haghgoshayie, E. (2019). Nursing' managers' perspectives on the facilitators and barriers to implementation of evidencebased management. Worldviews on Evidence-Based Nursing, 16(4), 255-262. https://dx.doi-org.sunypoly.idm.oclc. org/10.1111/wvn. 12372

Hasson, F., Keeney, F., \& McKenna, S. (2000). Research guidelines for the Delphi survey technique. Journal of Advanced Nursing, 32(4), 1008-1015. https://doi.org/10.1046/j.1365-2648.2000. t01-1-01567.x

Heydari, A., Mazlom, S.R., Ranjbar, H., \& Scurlock-Evans, L. (2014). A study of Iranian nurses' and midwives' knowledge, attitudes, and implementation of evidence-based practice: the time for change has arrived. Worldviews on Evidence-Based Nursing, 11(5), 325-31. https://dx.doi.org/10.1111/wvn.12052

Kim, S. C., Ecoff, L., Brown, C. E., Gallo, A. M., Stichler, J. F., \& Davidson, J. E. (2017). Benefits of a regional evidencebased practice fellowship program: A test of the ARCC Model. Worldviews on Evidence-Based Nursing, 14, 90-98. https:// dx.doi.org/10.1111/wvn.12199

Klimek Yingling, J. (2020). Rationing Evidence-Based Nursing Practice: Considering a Resource-Based Approach. The Online Journal of Issues in Nursing, 26,(1). https://dx.doi. org/10.3912/OJIN.Vol26No01PPT62

Levin, R. F., Wright, F., Pecoraro, K., \& Kopec, W. (2016). Maintaining perioperative normothermia: Sustaining an evidence-based practice improvement project. AORN Journal, 103(2), 213-e1. https://dx.doi.org/10.1016/j.aorn.2015.12.020

McPherson, S., Reese, C., \& Wendler. C. (2018). Methodology update: Delphi studies. Nursing Research, 67(5), 404-410. https://dx.doi.org/10.1097/NNR.0000000000000297

Melnyk, B.M. \& Fineout-Overholt, E. (2015). Making the case for evidence-based practice and cultivating a spirit of inquiry. In Evidence-based practice in nursing and healthcare: A guide to best practice (3rd ed, pp. 3-23). Wolters Kluwer.

Melnyk, B.M., Fineout-Overholt, E., Gallagher-Ford, L., \& Kaplan, L. (2012). The State of evidence-based practice in US nurses: Critical implications for nurse leaders and educators. Journal of Nursing Administration, 42(9), 410-417. https:// dx.doi.org/10.1097/nna.0b013e3182664e0a 
Melnyk, B. M., Fineout-Overholt, E., Giggleman, M., \& Choy, K. (2017). A test of the ARCC model improves the implementation of evidence-based practice, healthcare culture, and patient outcomes. Worldviews on Evidence-Based Nursing, 14(1), 5-9. https://dx.doi.org/10.1111/wvn. 12188

Melnyk, B. M., Gallagher- Ford. L., Thomas, B. K., Troseth, M., Wyngarden, K., \& Szalacha, L. (2016). A study of chief nurse executives indicates low prioritization of evidence-based practice and shortcomings in hospital performance metrics across the United States. Worldviews on Evidence-Based Nursing, 13(1), 6-14. https://dx.doi.org/10.1111/wvn.12133

Melnyk, B. M., Zellefrow, C., Tan, A., \& Hsieh, A. P. (2020). Differences between magnet and non-magnet-designated hospitals in 'nurses' evidence-based practice knowledge, competencies, mentoring and culture. Worldviews on EvidenceBased Nursing, 17(5),337-347. https://dx.doi.org/10.1111/ wvn. 12467

Renolen, A., Hoye, S., Hjälmhult, E., Danbolt, L., \& Kirkevold, M.(2018). Keeping on Track - hospital nurses' struggles with maintaining workflow while seeking to integrate evidencebased practice into their daily work: A grounded theory study. International Journal of Nursing Studies, 77,179-188. https:// dx.doi.org/10.1016/j.ijnurstu.2017.09.006.

Ryan-Madonna, M.,Levin, R.F., \& Lauder, B. (2019).Effectiveness of the teach-back method for improving 'caregivers' confidence in caring for hospice patients and decreasing hospitalizations. Journal of Hospice \& Palliative Nursing, 21(1), 61-70. https:// dx.doi.org/10.1097/njh.0000000000000492
Sidani, S., Manojlovich, M., Doran, D., Fox, M., Covell, C., Kelly, H., Jeffs, L., \& McAllister, M. (2016). Nurses' perceptions of interventions for the management of patientoriented outcomes: A key factor for evidence-based practice. Worldviews on Evidence-Based Nursing, 13(1), 66-74. https:// dx.doi.org/10.1111/wvn.12129

Smiley, R.A., Lauer, P., Bienemy, C., Berg, J.G., Shireman, E., Reneau, K.A., \& Alexander, M. (2018). The 2017 national nursing workforce survey. Journal of Nursing Regulation, 9(3), supplement (S1-S54). https://dx.doi.org/10.1016/S21558256(18)30131-5

Välimäki, T., Partanen, P., \& Häggman, L. A. (2018). An integrative review of interventions for enhancing leadership in the implementation of evidence-based nursing. Worldviews on Evidence-Based Nursing, 15(6), 424-431. https://dx.doi. org/10.1111/wvn.12331

Warren, J. I., McLaughlin, M., Bardsley, J., Eich, J., Esche, C.A., Kropkowski, L \& Risch, S. (2016). The strengths and barriers of implementing EBP in healthcare systems. Worldviews on Evidence-Based Nursing, 13(1), 15-24. https://dx.doi. org/10.1111/wvn.12149

Wilson, M., Sleutel, M., Newcomb, P., Behan, D., Walsh, J., Wells, J., \& Baldwin, K. (2015). Empowering nurses with evidencebased practice environments: Surveying Magnet, Pathway to Excellence, and non-magnet facilities in one healthcare system. Worldviews Evidence-Based Nursing, 12(1), 12-21. https://dx.doi.org/10.1111/wvn.12077 


\title{
Technology Use and Frailty for Community Dwelling Older Adults: A Scoping Review
}

\author{
Chava Pollak ${ }^{1 *} \&$ Sharon Wexler ${ }^{1}$ \\ ${ }^{1}$ Pace University, New York, NY, USA \\ *Corresponding Author - Chava Pollak, Pace University, New York, USA. Email: cs68128p@ pace.edu \\ DOI: https://dx.doi.org/10.47988/janany.44473381.1.1
}

\begin{abstract}
Background: Frailty is a common geriatric syndrome defined as a state of increased vulnerability to acute stressors related to a decline in reserve. There is abundant literature on frailty interventions, however, the literature on technology as an intervention for frailty is scarce.
\end{abstract}

Objectives: The purpose of this scoping review is to identify and summarize existing evidence on technology use as an intervention for frail older adults and to identify research gaps in the evidence base in order to inform future research.

Methodology: This review utilized the Preferred Reporting Items for Systematic Reviews and Meta-Analyses (PRISMA) guidelines and a rigorous scoping review method to search the literature. A comprehensive search of computerized databases was conducted in July 2018 in the following databases published from 2013 to 2018 : CINAHL, PubMed, and Academic Search Complete.

Results: The database searches yielded a total of 183 articles. Forty-four duplicates were removed. There were 114 results excluded based on title and abstract ineligibility. Thirty-two relevant articles were retrieved for fulltext examination. Eighteen of the articles were excluded based on the inclusion or exclusion criteria. References of 14 included articles were hand-searched for relevant works to ensure completeness of the search. Four pertinent additional articles were identified. The final analysis included 18 articles.

Discussion: Current research on technology use for frail older adults focuses on assessment and diagnosis. Methodological weaknesses limit generalizability and the validity of its findings. Few studies utilize frailty as an outcome measure, limiting available research directly related to frailty.

Conclusion: More research is needed on the potential for technological tools as interventions for frailty in older adults living at home, specifically, to prevent pre-frailty and frailty.

Keywords: frailty, frail elderly, aged, independent living, technology

Funding: The authors did not receive any funding from the public, commercial, or not-for-profit sectors.

Conflict of Interest: The authors declare no actual or potential conflict of interest. 


\section{Technology Use and Frailty for Community Dwelling Older Adults: A Scoping Review}

Frailty is a common geriatric syndrome, defined as a clinically recognizable state of increased vulnerability to adverse outcomes related to a decline in reserve across multiple systems, diminishing the ability to respond to acute, even minor, stressors such as surgery, loss of a spouse, minor infection, or change in medication regimen (Clegg et al., 2013). This decline in reserve places the individual at greater risk for poor health outcomes, including falls, disability, hospitalization, institutionalization, and mortality (Buckinx et al., 2015; Chang \& Lin, 2015; Fried et al., 2001; Kane et al., 2012; Xue, 2011). Pre-frailty is a term used to describe a state of elevated risk for frailty where significant functional decline is not yet evident (Fried et al., 2001). This early stage represents a crucial intervention point when preventative measures would be most effective to implement. Frailty is a dynamic, reversible process with the potential for improvement, rather than an inevitable spiral of decline (Conroy \& Elliot, 2016). Individuals transition between frailty states with potential for recovery from frail, pre-frail to robust status (Siriwardhana et al., 2018). This review focuses on community-dwelling older adults, defined as older adults living independently in the community, because this population is more commonly pre-frail, and will therefore potentially benefit most from early identification and intervention (Feng et al., 2017; Xue, 2011).

\section{Background}

Currently, there is no clear consensus regarding the definition of frailty, creating challenges in the identification and evaluation of frailty in older adults. However, it is commonly agreed that frailty is a clinically recognizable state of increased vulnerability to adverse outcomes related to a decline in physiologic reserve (Rockwood \& Mitnitski, 2011; Siriwardhana et al., 2018). This is the definition of frailty that will be used for the purposes of this review.

The two most commonly used definitions of frailty are the Fried phenotype and the Frailty Index (FI) (Clegg et al., 2013; Kojima et al., 2018; Siriwardhana et al., 2018). The frailty phenotype defines frailty as a condition meeting three out of five phenotypic criteria including weight loss, exhaustion, low physical activity, slowness and weakness, reflecting underlying loss of physiologic reserve (Fried et al., 2001). The phenotype further identifies three stages of frailty, ranging from robust, pre-frail, and frail (Fried et al., 2001). The pre-frail stage is a transitional state, where one or two criteria are present and suggests a higher risk of progression to frailty (Fried et al., 2001). Critique of this definition is that it is limited to physiologic and functional domains and does not reflect the multi-dimensional nature of the frailty syndrome. With complex, multifactorial geriatric syndromes such as frailty, it is crucial to consider relevant domains outside of a discrete biological framework (Inouye et al., 2007).

The FI measures frailty by the number of accumulated deficits across multiple domains, including physical and cognitive impairment, comorbidities, disability, psychosocial risk factors, and geriatric syndromes such as falls, delirium, and incontinence (Rockwood \& Mitnitski, 2011). The increased number of deficits are predictive of adverse health outcomes, including mortality (Kojima et al., 2018; Mitnitski et al., 2017). People, on average accumulate deficits as they age, however, the nature of the deficit and the rate at which they accumulate varies from person to person, reflecting the heterogeneity and complexity of the frailty phenomenon (Rockwood \& Mitnitski, 2011). The use of the FI requires a comprehensive geriatric assessment (Rockwood \& Mitnitski, 2011), thus limiting its practicality in everyday clinical practice due to potential time constraints.

In the absence of a gold standard defining frailty, prevalence rates vary widely from $4-59 \%$ across multiple frailty measures (Buckinx et al., 2015; Collard et al., 2012), presenting a potentially considerable population at risk. Trends suggest frailty increases with age, affects more women than men, is greater among African Americans than Caucasians, and is more prevalent among people with lower education, lower income, and higher rates of comorbidities (Buckinx et al., 2015; Collard et al., 2012; Feng et al., 2017; Xue, 2011). Additionally, nursing home residents are more likely to be frail than community-dwelling people; however, institutionalization could be a consequence of frailty itself (Buckinx et al., 2015). Frailty is a public health concern as it identifies individuals with a greater need for healthcare intervention and at high risk for dependency (Buckinx et al., 2015). Frailty is associated with disability in activities of daily living (ADLs), which are crucial for the maintenance of independent living (Kojima, 2017; Provencher et al., 2017). Since many older adults prefer to live at home, this represents a crucial intervention area to promote quality of life in this population.

Interventions to prevent and ameliorate frailty can improve older adults' lives, improve health, reduce adverse outcomes, and allow for maintenance of an independent lifestyle. A review of available literature reveals plentiful research on frailty interventions. Several systematic reviews and meta-analyses examined existing evidence for multiple frailty interventions (Apostolo et al., 2018; Chang \& Lin, 2015; De Labra et al., 2015; De Vries et al., 2012; Puts et al., 2017; Silva et al., 2018; Theou et al., 2011). Studies indicated physical exercise effectively improved mobility and functional status in frail older adults (De Labra et al., 2015; De Vries et al., 2012). Nutritional interventions, such as protein supplementation, were also useful for targeting specific frailty markers, including nutritional deficiencies and weight loss (Apostolo et al., 2018). Multifactorial, multidisciplinary interventions were most effective in reducing frailty levels, specifically combined nutrition and exercise interventions (Apostolo et al., 2018; De Labra, 2015). Notably, there is little mention of technology as an intervention for frailty in the literature. Several recent studies explored the potential for technology as a tool for enhancing independence and quality of life, reducing healthcare costs by preventing and managing disability, along with frailty in the elderly (Pilotto et al., 2018). Domestic appliances that control and manage the physical environment can maintain and improve functional capacity in older adults living at home, such as sensor technology to detect fall risk and improve gait and mobility (Pilotto et al., 2018). Wearable technologies allow for remote evaluation and monitoring of frailty 
and fall risk during daily activities, enabling early intervention (Armstrong et al., 2017). Most older adults prefer to live at home, and new and emerging technologies can help them do so safely and independently.

\section{The Review}

\section{Aims}

The purpose of this scoping review is to identify and summarize existing evidence relevant to technology use for frail, communitydwelling older adults in order to highlight areas of opportunity for future research. Specifically, this review focuses on technologies described in the literature for identification, assessment, prevention, and treatment for community-dwelling older adults with frailty, for use primarily by the older adults themselves. The expected increase in the elderly population will impact society in terms of increasing numbers of frail older adults with substantial need for support and interventions. Technological innovations may represent novel solutions to maintain functional abilities and independence for older adults living at home.

\section{Design}

This review used the Preferred Reporting Items for Systematic Reviews and Meta-Analyses (PRISMA) guidelines (Tricco et al., 2018) and a rigorous scoping review method to search the literature (Figure 1). The scoping review method was chosen because it is ideal for an emerging and critically under-researched area to identify trends and gaps in the literature to inform future researchers (Arksey \& O'Malley, 2005). The research question that guided this review was, "What are the current practices, standard use, and recommendations for technology use for frail, community-dwelling older adults?" The following steps were used to conduct the search: 1) identify the research question, 2) identify relevant studies, 3) study selection, 4) organize the data, and 5) summarize the results.

\section{Figure 1}

\section{PRISMA Search Strategy Flow Chart}

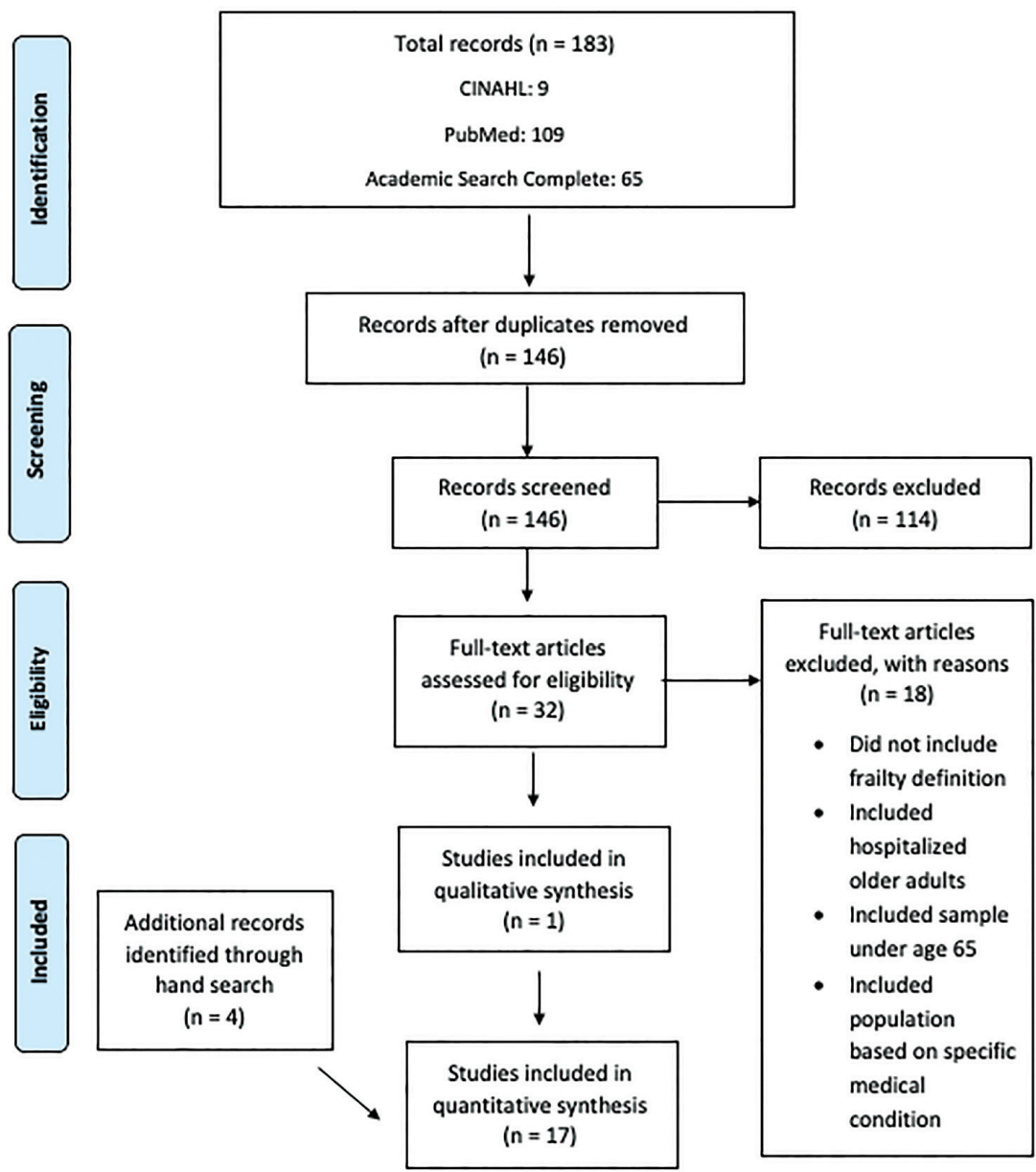

Note. From "PRISMA extension for scoping reviews (PRISMA-ScR): Checklist and explanation," by Tricco, A.C., Lillie, E., Zarin, W., O’Brien, K.K., Colquhoun, H., Levac, D.,...Straus, S.E. 2018, Annals of Internal medicine, 169, 467-473. (https://doi:10.7326/ M18-0850). 


\section{Search Methods}

After several preliminary searches to identify keywords and gain familiarity with the literature, a comprehensive search of computerized databases was conducted in July 2018 in the following databases published from 2013 to 2018: CINAHL, PubMed, and Academic Search Complete. Related subject headings, MeSH terms, and keywords were identified in consultation with research librarians to capture a comprehensive list of potential sources. MeSH terms were identified and used to search the PubMed database. Keywords and subject headings were used for CINAHL and Academic Search Complete (Table 1). Finally, keywords were identified and combined to address all components of the research question: 1) elderly, 2) frailty, 3) community-dwelling, and 4) technology. The search strategy was designed to identify studies that used technology with a population of frail older adults aged 65 and over living in the community.

\section{Table 1}

\section{Search Terms}

\begin{tabular}{|c|c|c|c|}
\hline Elderly & Frailty & $\begin{array}{l}\text { Community } \\
\text { Dwelling }\end{array}$ & Technology \\
\hline $\begin{array}{l}\text { Aged [Mesh] } \\
\text { (SH) } \\
\text { Aged, } 80 \text { and } \\
\text { over }[\mathrm{MeSH}] \\
\text { frail elderly } \\
{[\mathrm{MeSH}](\mathrm{SH})} \\
\text { older adults } \\
(\mathrm{KW})\end{array}$ & $\begin{array}{l}\text { Frailty } \\
{[\mathrm{MeSH}]} \\
\text { Frailty } \\
\text { syndrome } \\
(\mathrm{SH}) \\
\text { Frail (KW) } \\
\text { prefrail } \\
(\mathrm{KW}) \\
\text { prefrailty } \\
(\mathrm{KW})\end{array}$ & $\begin{array}{l}\text { community } \\
\text { living (SH) } \\
\text { community } \\
\text { dwelling } \\
\text { (KW) } \\
\text { Independent } \\
\text { Living } \\
\text { [MeSH] } \\
\text { Residence } \\
\text { characteristics } \\
{[\mathrm{MeSH}]}\end{array}$ & $\begin{array}{l}\text { Geriatrics/ } \\
\text { instrumentation } \\
\text { [MeSH]) } \\
\text { Technology } \\
\text { [Mesh] (SH) } \\
\text { Assistive } \\
\text { technology } \\
\text { (SH) } \\
\text { Telehealth (SH) } \\
\text { Ehealth (KW) } \\
\text { Mhealth (KW) } \\
\text { Telemedicine } \\
\text { [MeSH] (SH) } \\
\text { Wearable } \\
\text { electronic } \\
\text { devices [MeSH] } \\
\text { Remote } \\
\text { monitoring } \\
\text { (KW) } \\
\text { Virtual reality } \\
\text { [MeSH] } \\
\text { Robotics } \\
\text { [MeSH] } \\
\text { Smartphone } \\
\text { [MeSH] }\end{array}$ \\
\hline
\end{tabular}

Note. $\mathrm{KW}=$ Keyword; $\mathrm{SH}=$ Subject Heading; $\mathrm{MeSH}=$ Medical Subject Heading

Articles were included if they met the following criteria: 1) focused on adults aged 65 and over living in the community; 2) peer-reviewed; 3) published in the English language; 4) featured randomized controlled trials (RCTs), cohort studies, or qualitative research; and 5) include an operationalized definition of frailty. These criteria were chosen to meet this review's focus, namely technologies used for frail older adults living at home. The search was limited to the years 2013-2018 for practicality, to identify how technology was most recently used for the study population. Articles were excluded if they: 1) focused on adults younger than 65 or children; 2) included hospitalized older adults; 3) were published in a language other than English; 4) were study protocols, conference abstracts, unpublished dissertations or commentaries; 5) were measurement tool use or development studies; or 6) selected the target population based on the presence of a specific medical condition. As the search evolved, inclusion and exclusion criteria were revised to best address the research question (Table 2).

\section{Table 2}

\section{Inclusion and Exclusion Criteria}

\begin{tabular}{|l|l|}
\hline Inclusion & Exclusion \\
\hline $\begin{array}{l}\text { Older adults over the age of } \\
\text { 65 living in the community }\end{array}$ & Adults under 65 or children \\
\hline Peer-reviewed & $\begin{array}{l}\text { Hospitalized/institutionalized } \\
\text { older adults }\end{array}$ \\
\hline English language & $\begin{array}{l}\text { Published in non-English } \\
\text { language }\end{array}$ \\
\hline $\begin{array}{l}\text { RCT, cohort studies or } \\
\text { qualitative research }\end{array}$ & $\begin{array}{l}\text { Systematic review, study } \\
\text { protocols, conference } \\
\text { abstracts, unpublished } \\
\text { dissertations or commentaries }\end{array}$ \\
\hline $\begin{array}{l}\text { Operationalized definition of } \\
\text { frailty }\end{array}$ & $\begin{array}{l}\text { Measurement tool use or } \\
\text { development studies }\end{array}$ \\
\hline & $\begin{array}{l}\text { Selected the target population } \\
\text { based on the presence of a } \\
\text { specific medical condition }\end{array}$ \\
\hline
\end{tabular}

\section{Search Outcomes}

The database searches, as described above yielded a total of 183 articles. There were 41 duplicates, which were removed. One hundred fourteen of the results were excluded based on title and abstract. Thirty-two articles relevant to this review were retrieved for full-text examination. Eighteen of the articles were excluded based on inclusion or exclusion criteria. Fourteen of the articles met all inclusion criteria. References of those articles were then hand searched for relevant works to ensure the completeness of the search, after which four additional relevant articles were identified. The final analysis included 18 articles from several different countries including Ireland $(n=2)$, Japan $(n=1)$, Spain $(\mathrm{n}=4)$, the Netherlands $(\mathrm{n}=3)$, and the United States $(\mathrm{n}=8)$ (Table 3).

\section{Results/Synthesis}

The small number of studies included in this review indicates research on technology use for community-dwelling frail older adults with confirmed frailty status is limited. Analysis of included studies is organized by their objectives, namely frailty assessment, frailty intervention, and technology use. Studies are further grouped by assessment methods such as gait parameters, performance-based measures, and upper extremity frailty. An additional subheading was included to assess studies that 
examined frailty proxy measures such as fall risk. The technology use category includes qualitative data on the use of technology in older adults.

\section{Frailty Intervention}

The impact of technology-supported, home-based exercise programs for frail older adults were evaluated (Dekker-van Weering et al., 2017; Garaedts et al., 2017). The studies were designed for the frail elderly living at home but did not measure frailty as an outcome. Instead, the studies used a frailty measure to identify frail individuals as part of inclusion criteria, however, frailty status was not measured as an outcome of the intervention. Studies used outcome measures such as gait performance, muscle strength, physical performance tests such as the Times Up and Go (TUG) test, which tangentially include aspects of frailty but fail to use a standardized frailty measure. Other outcome measures included adherence to an intervention such as an exercise program or user opinion regarding a proposed intervention. These research studies concluded that a combination of strength and balance training was most effective in addressing frailty in older adults (Dekker-van Weering et al., 2017; Geraedts et al., 2017; Ozaki et al., 2017). Internet connectivity was a common problem with home-based technologies and was noted as an important factor in study dropout rates (Geraedts et al., 2017). The long-term impact of technology-based exercise interventions was not evaluated.

\section{Frailty Assessment}

The most commonly used frailty definition in the included research was the Fried phenotype criteria (Galan-Mercant \& Cuesta-Vargas, 2013; Galan-Mercant \& Cuesta-Vargas, 2014; Galan-Mercant \& Cuesta-Vargas, 2015; Greene et al., 2014a; Greene et al., 2014b; Martinez-Ramirez et al., 2015; Mohler et al., 2016; Muchna et al., 2018; Ozaki et al., 2017; Parvaneh et al., 2017; Rahemi et al., 2018; Razjouyan et al., 2018; Rye-Hanton et al., 2017; Toosizadeh et al., 2015). Twelve articles included in this review discussed technology-based assessment, diagnosis, and classification of frailty. Four of these studies examined different aspects of frailty in subsamples of the same cohort, namely, the Arizona Frailty Cohort (Mohler et al., 2016; Muchna et al., 2018; Schwenk et al., 2015; Toosizadeh et al., 2015). The instruments used for evaluation include body-worn sensors, sensors embedded in smartphones, and pendant sensors. The research studies evaluated various frailty-related parameters to complement or replace time and resource-intensive frailty assessment in the community setting. The use of these technologies for frailty identification was suggested as a tool for early identification of frailty during daily activities that may not be detectable on clinical exam in order to identify individuals who would benefit from early intervention.

\section{Gait Parameters}

Gait parameters were often used to identify frail individuals, as slowed gait and decreased muscle strength are known markers of frailty (Fried et al., 2001). Studies that evaluated pendant sensors, body sensors, as well as smartphone sensors identified specific gait parameters associated with frailty including, decreased step count, reduced gait speed, gait and stride irregularity, and decreased overall physical activity (Martinez-Ramirez et al., 2015; Rahemi et al., 2018; Razjouyan et al., 2018; Rye-Hanton et al., 2017; Schwenk et al., 2015). Various wearable and inertial sensors were used to identify individuals with frailty and distinguish between robust, pre-frail, and frail individuals. These sensors were suggested for use for remote frailty monitoring as the sensors can be worn at home and did not require skilled monitoring (Martinez-Ramirez et al., 2015; Rahemi et al., 2018; Razjouyan et al., 2018; Rye-Hanton et al., 2017; Schwenk et al., 2015).

\section{Performance-Based Measures}

Sensor-based measures of sit-to-stand and stand-to-sit transitions and the TUG test evaluated the use of wearable technology to complement or improve the accuracy of traditional frailty assessment methods (Galan-Mercant \& Cuesta-Vargas, 2015; Greene et al., 2014a; Greene et al., 2014b) or to allow for non-expert assessment in unsupervised settings (Greene et al., 2014a; Greene et al., 2014b). Smartphone embedded sensors and chest-worn sensors were sensitive for frailty identification by capturing postural position changes during functional tasks that individuals often perform during the day, such as rising from a chair and turning around while walking (Galan-Mercant \& Cuesta-Vargas, 2013; Parvaneh et al., 2017). Postural transitions and functional tasks were restricted in frail older adults as they compensated for frailty with increasingly careful movements (Galan-Mercant \& Cuesta-Vargas, 2013; Parvaneh et al., 2017).

Various sensors were used to identify frail individuals during the performance of functional tasks during physical performance tests, including the TUG test and the sit-to-stand test (GalanMercant \& Cuesta-Vargas, 2014; Galan-Mercant \& CuestaVargas, 2015; Greene et al., 2014a; Greene et al., 2014b). These studies identified individuals with frailty via body-worn sensor data alone (Galan-Mercant \& Cuesta-Vargas, 2014; GalanMercant and Cuesta-Vargas, 2015). They also validated use of these sensors for frailty identification compared to established frailty measures such as the Fried phenotype (Greene et al., 2014a; Greene et al., 2014b). These measures were important for homebased use as they can be helpful in identifying frailty during nonmonitored activities that individuals perform in their daily lives. Additionally, the technologies can be used by non-skilled users out of the clinical environment.

\section{Upper Extremity Frailty}

A study by Toosizadeh et al. (2015) presented an innovative method of identifying frailty categories using several upper extremity assessment parameters of elbow flexion. Results showed this upper extremity task discriminated between frailty groups; slowness discriminated between pre-frail and non-frail older adults, while weakness discriminated between pre-frail and frail older adults (Toosizadeh et al., 2015). This assessment method was proposed as advantageous over the standard Fried criteria assessment as a shorter and less strenuous task that still included several frailty markers (Toosizadeh et al., 2015). This method also did not include gait assessment, making it possible for use in individuals with gait problems or where inadequate space is available (Toosizadeh et al., 2015). 


\section{Frailty Proxy Measures}

Wearable sensors were operationalized as devices that evaluated various gait performance measures as predictors of fall risk (Mohler et al., 2016; Muchna et al., 2018). While participants were screened for frailty, this information was utilized to describe the sample rather than the study outcome (Mohler et al., 2016; Muchna et al., 2018). Falls are a known adverse outcome of frailty and, along with gait abnormalities, are often used as a proxy measure for frailty in studies.

\section{Level of Technology Use}

Only one study by Peek et al. (2016) qualitatively explored the level of technology use by older adults living at home. Six major themes influenced the level of technology use in the context of aging in place: challenges in the domain of independent living, the influence of the social network, the influence of organizations, and the role of the physical environment (Peek et al., 2016). This highlighted the importance of technological solutions to consider older adults' personal, social, and physical context to optimize use.

\section{Discussion}

The aim of this scoping review was to identify and summarize existing evidence related to technology use for frail older adults living at home and to highlight research gaps in the evidence base. This review included studies that explored technologies used by older adults themselves, rather than peripheral technologies that individuals would not directly engage with, such as home monitoring systems. The purpose was to identify what technologies are currently being used for the frail older adult population and identify areas of opportunity for future research on other technologies that will maintain and increase the independence of frail older adults living at home.

Research on technology for frail older adults living at home is heavily dominated by methods for frailty assessment and identification. Only three studies in this review focused on technologies for use as an intervention for frailty in communitydwelling older adults (Dekker-van Weering, 2017; Garaedts, 2017; Ozaki et al., 2017). Furthermore, there is an added emphasis on using technologies to identify pre-frailty as a critical point for preventing and reversing frailty progression. Technologies can do this more efficiently and effectively than clinical evaluation as they can capture subtle changes in strength, functional performance, and gait. Wearable sensors and those embedded in smartphones offer tremendous potential to measure an individual's daily activity over prolonged periods in a non-invasive, inexpensive manner. Parameters that identify pre-frailty are particularly pivotal in this sense. Pre-frailty presents a decisive intervention point to prevent a spiral decline into frailty or to halt the progression of functional decline (Xue, 2011). Home-based sensors offer a possible solution for capturing subtle changes in individual behaviors that may not be evident during a routine clinical assessment and may signify muted indications of health status deterioration.

Following frailty identification, intervention is essential to prevent functional decline. However, there is a dearth of available evidence on the application of technology as an intervention for frailty in community-dwelling older adults, especially interventions measuring frailty as an outcome. Technology administered or facilitated exercise programs may enable broader access to this intervention for older adults who have difficulty leaving home due to mobility or transportation issues. Various technologies can also provide remote, automated coaching to reduce the need for skilled, real-time assistance. Social interventions can also be deployed remotely, giving access to online group activities when an in-person meeting is not possible. This highlights an area of opportunity for future research to develop and apply innovative technologies as an intervention for frailty. Additionally, many studies evaluating technology for community-dwelling frail older adults took place in a laboratory setting, not in a real home setting, where actual implementation and conditions are unclear. Additional research is needed to imagine the future implementation of these technologies for individuals in their homes. Moreover, older adults' input should be considered when developing interventions to improve acceptability and usability.

Areas for future research include studies with larger sample sizes, and samples that include older adults with cognitive impairment. Many studies with frail older adults included small sample sizes. Larger studies are needed to improve the generalizability and validity of research outcomes. Additionally, older adults with cognitive impairment are notably missing from study samples evaluating the use of technology in cohorts of frail elderly. Cognitive frailty, or the simultaneous presence of physical frailty and cognitive impairment in older adults without a diagnosis of dementia, is an important aspect of frailty (Robertson et al., 2013) and bears further evaluation in future studies. Frailty and cognitive impairment are related, but distinct concepts that frequently co-exist (Robertson et al., 2013). The inclusion of individuals with cognitive impairment in future frailty studies is certainly warranted.

The findings of this review are especially important in light of the COVID-19 pandemic, where the toll of necessary public health measures to contain the pandemic, such as physical distancing and isolation on older adults, is yet unknown and potentially catastrophic in terms of functional deterioration, increased loneliness, and mental health challenges. These challenges highlight the necessity of technological solutions to address the needs of frail older adults living at home. This review highlights the various technologies already explored for use in the home and sheds light on how these technologies can be used in the future to meet the essential needs of frail older adults in the community. This includes remote monitoring for frailty assessment and technologically administered interventions (e.g., exercise interventions) to maintain physical function while isolating in the home and social and cognitive interventions to address the holistic needs of this population.

\section{Limitations}

Inclusion criteria in terms of types of studies included in this review were narrow, and content available in abstracts, editorials, and dissertations may have broadened the findings. Additionally, limiting inclusion to English language articles potentially eliminated relevant articles written in other languages. The narrow inclusion criteria were purposeful in the sense that this review sought to identify a very particular population at risk, namely 
adults over the age of 65 living at home, and how technology was used in this population. However, this does eliminate a larger risk pool of individuals that may warrant further study in a different context. This review also sought to identify technology used in this population, particularly those that older adults interact with directly as an intervention for frailty. Articles that discussed technologies not used by the older adult, such as those used by caregivers or healthcare providers in the service of frail older adults, were excluded. These technologies were therefore not captured in this review but may be useful for future research.

Importantly, although all studies in this review include a sample of frail older adults, none measured frailty as an outcome. Instead, studies used various gait parameters and performance measures as the study outcomes. Additionally, while there is no uniform measure for frailty employed by all studies included in this review, the Fried phenotype is used more than any other frailty definition. Some studies use frailty proxy measures such as physical disability,
ADL disability, falls, or gait parameters in place of discrete frailty assessment. The variable definitions and frailty measures employed in the literature make it difficult to cumulatively and quantitatively analyze the evidence base in this area.

\section{Conclusion}

Various effective interventions for frailty are well established in the literature. The use of technology for frail older adults is heavily concentrated on the assessment and diagnosis of frailty. More research is needed on the potential for technological tools as interventions for frailty in community-dwelling elderly, specifically for detecting and preventing pre-frailty and frailty. Future studies should include adequate sample sizes to improve the validity and generalizability of results, a focus on frail older adults with cognitive impairment, and an examination of interventions using frailty as a variable to refine the applicability and practical application of the results to the frail elderly population.

Table 3

Summary of Included Literature

\begin{tabular}{|c|c|c|c|c|}
\hline $\begin{array}{l}\text { Authors, Year, } \\
\text { Country }\end{array}$ & Design & Purpose & Sample & Results \\
\hline $\begin{array}{l}\text { Dekker-van Weering } \\
\text { et al. (2017), The } \\
\text { Netherlands }\end{array}$ & $\begin{array}{l}\text { Randomized } \\
\text { controlled trial }\end{array}$ & $\begin{array}{l}\text { To investigate the use and } \\
\text { user experience of an online } \\
\text { home-based exercise program } \\
\text { and to determine whether the } \\
\text { intervention improved quality of } \\
\text { life and health status of pre-frail } \\
\text { older adults compared to a control } \\
\text { group. }\end{array}$ & $\begin{array}{l}37 \text { pre-frail } \\
\text { community dwelling } \\
\text { older adults } \\
\text { Age } 65-75 \\
16 \text { experimental } \\
21 \text { control }\end{array}$ & $\begin{array}{l}\text { A home-based exercise } \\
\text { program is easy to use and } \\
\text { has potential in improving } \\
\text { quality of life and health } \\
\text { status in pre-frail older } \\
\text { adults living at home. }\end{array}$ \\
\hline $\begin{array}{l}\text { Galan-Mercant and } \\
\text { Cuesta-Vargas (2013), } \\
\text { Spain }\end{array}$ & $\begin{array}{l}\text { Cross-sectional } \\
\text { study }\end{array}$ & $\begin{array}{l}\text { To describe the variability of the } \\
\text { accelerations, angular velocity } \\
\text { and displacement of the trunk } \\
\text { during the sit to stand and stand } \\
\text { to sit transitions in two groups of } \\
\text { frail and physically active elderly } \\
\text { persons through instrumentation } \\
\text { with the smartphone. }\end{array}$ & $\begin{array}{l}30 \text { older adults } \\
\text { Age }>65 \\
14 \text { frail } \\
16 \text { non-frail }\end{array}$ & $\begin{array}{l}\text { The inertial sensor fitted } \\
\text { in the iPhone } 4 \text { can } \\
\text { analyze kinematics of the } \\
\text { Si-St and St-Si transitions } \\
\text { in frail and robust older } \\
\text { adults to discriminate } \\
\text { between the two groups. }\end{array}$ \\
\hline $\begin{array}{l}\text { Galan-Mercant and } \\
\text { Cuesta-Vargas (2014), } \\
\text { Spain }\end{array}$ & $\begin{array}{l}\text { Cross-sectional } \\
\text { study }\end{array}$ & $\begin{array}{l}\text { To measure and describe the } \\
\text { variability of acceleration, angular } \\
\text { velocity and trunk displacement } \\
\text { in the } 10 \mathrm{~m} \text { TUG test through } \\
\text { instrumentation with the iPhone } 4 \text {. }\end{array}$ & $\begin{array}{l}30 \text { older adults } \\
\text { Age }>65 \\
14 \text { frail } \\
16 \text { non-frail }\end{array}$ & $\begin{array}{l}\text { The inertial sensor in the } \\
\text { iPhone } 4 \text { is capable of } \\
\text { studying and analyzing } \\
\text { the kinematics of the TUG } \\
\text { test in frail and non-frail } \\
\text { elderly; allows for more } \\
\text { sensitive differentiation } \\
\text { between the two groups } \\
\text { than the traditionally used } \\
\text { variable of time. }\end{array}$ \\
\hline
\end{tabular}




\begin{tabular}{|c|c|c|c|c|}
\hline $\begin{array}{l}\text { Galan-Mercant and } \\
\text { Cuesta-Vargas (2015), } \\
\text { Spain }\end{array}$ & $\begin{array}{l}\text { Cross-sectional } \\
\text { study }\end{array}$ & $\begin{array}{l}\text { To determine the series of } \\
\text { kinematic variables with } \\
\text { the greatest precision in } \\
\text { discriminating between frail } \\
\text { and non-frail elderly in the } 10 \mathrm{~m} \\
\text { TUG test using inertial sensors } \\
\text { embedded in the iPhone } 4 \\
\text { compared to the traditional time } \\
\text { variable. }\end{array}$ & $\begin{array}{l}30 \text { older adults } \\
\text { Age }>65 \\
14 \text { frail } \\
16 \text { non-frail }\end{array}$ & $\begin{array}{l}\text { Kinematic variables } \\
\text { obtained from inertial } \\
\text { sensors embedded in } \\
\text { smartphone technology } \\
\text { during the TUG test can } \\
\text { discriminate between } \\
\text { frailty status. }\end{array}$ \\
\hline $\begin{array}{l}\text { Geraedts et al. (2017), } \\
\text { The Netherlands }\end{array}$ & $\begin{array}{l}\text { Prospective } \\
\text { cohort study }\end{array}$ & $\begin{array}{l}\text { To evaluate the feasibility and user } \\
\text { opinion of a home-based exercise } \\
\text { program supported by a sensor } \\
\text { and tablet application }\end{array}$ & $\begin{array}{l}40 \text { frail, community } \\
\text { dwelling older adults } \\
\text { Age }>70 \\
\text { Ability to walk } \\
\text { 10m independently or } \\
\text { with walking aid }\end{array}$ & $\begin{array}{l}\text { A home-based exercise } \\
\text { program using novel } \\
\text { technology is feasible. } \\
\text { Regular coaching has } \\
\text { a positive influence on } \\
\text { adherence. }\end{array}$ \\
\hline $\begin{array}{l}\text { Greene, Doheny, } \\
\text { Kenny and Caufield } \\
\text { (2014), Ireland }\end{array}$ & $\begin{array}{l}\text { Observational, } \\
\text { cross-sectional } \\
\text { study }\end{array}$ & $\begin{array}{l}\text { To investigate the combination } \\
\text { of assessments of frailty and falls } \\
\text { risk in older adults. }\end{array}$ & $\begin{array}{l}130 \text { community } \\
\text { dwelling older adults } \\
\text { Age }>65 \\
\text { Ability to walk } \\
\text { without assistance }\end{array}$ & $\begin{array}{l}\text { Sensor data obtained from } \\
3 \text { physical assessments } \\
\text { resulted in improved } \\
\text { classification of falls risk } \\
\text { and frailty. }\end{array}$ \\
\hline $\begin{array}{l}\text { Greene, Doheny, } \\
\text { O'Halloran and } \\
\text { Kenny (2014), Ireland }\end{array}$ & $\begin{array}{l}\text { Observational, } \\
\text { cross-sectional } \\
\text { study }\end{array}$ & $\begin{array}{l}\text { To investigate a fast method for } \\
\text { automatic, quantitative assessment } \\
\text { of the frailty state based on a } \\
\text { simple protocol employing body } \\
\text { worn inertial sensors }\end{array}$ & $\begin{array}{l}399 \text { community } \\
\text { dwelling older adults } \\
\text { Age }>60 \\
30 \text { frail } \\
185 \text { pre-frail } \\
184 \text { non-frail } \\
115 \text { male } \\
284 \text { female }\end{array}$ & $\begin{array}{l}\text { Assessment with well- } \\
\text { known TUG mobility test } \\
\text { and inertial sensors can } \\
\text { be a fast, effective way of } \\
\text { non-expert assessment of } \\
\text { frailty }\end{array}$ \\
\hline $\begin{array}{l}\text { Martinez-Ramirez et } \\
\text { al. (2015), Spain }\end{array}$ & $\begin{array}{l}\text { Observational, } \\
\text { cross-sectional } \\
\text { study }\end{array}$ & $\begin{array}{l}\text { To investigate whether a } \\
\text { collection of parameters extracted } \\
\text { from the trunk acceleration } \\
\text { signals could provide additional } \\
\text { accurate information about frailty } \\
\text { syndrome. }\end{array}$ & $\begin{array}{l}718 \text { older adults } \\
319 \text { males } \\
399 \text { females } \\
\text { Age } 75.4+/-6.1 \\
\text { Ability to complete } \\
3 \mathrm{~m} \text { walk test at their } \\
\text { own gait velocity }\end{array}$ & $\begin{array}{l}\text { Gait parameters } \\
\text { simultaneously used } \\
\text { with gait velocity can be } \\
\text { used to more accurately } \\
\text { classify frailty status; may } \\
\text { allow for early detection } \\
\text { of pre-frailty. }\end{array}$ \\
\hline $\begin{array}{l}\text { Mohler et al. (2016), } \\
\text { USA }\end{array}$ & $\begin{array}{l}\text { Observational } \\
\text { descriptive } \\
\text { study }\end{array}$ & $\begin{array}{l}\text { To evaluate wearable sensor- } \\
\text { based measures of gait, balance, } \\
\text { and physical activity that are } \\
\text { predictive of future falls in } \\
\text { community-dwelling older adults. }\end{array}$ & $\begin{array}{l}119 \text { community } \\
\text { dwelling older adults } \\
\text { Age }>65\end{array}$ & $\begin{array}{l}\text { The association between } \\
\text { motor performance } \\
\text { and risk of falling is } \\
\text { dependent on frailty } \\
\text { status. Wearable sensor } \\
\text { is a tool for assessing fall } \\
\text { risk in the home setting. }\end{array}$ \\
\hline $\begin{array}{l}\text { Muchna et al. (2018), } \\
\text { USA }\end{array}$ & $\begin{array}{l}\text { Observational } \\
\text { descriptive } \\
\text { study }\end{array}$ & $\begin{array}{l}\text { To examine the effect of foot } \\
\text { problems on the likelihood of } \\
\text { falls, frailty syndrome, motor } \\
\text { performance and physical activity } \\
\text { in community dwelling older } \\
\text { adults. }\end{array}$ & $\begin{array}{l}117 \text { community } \\
\text { dwelling older adults } \\
41 \text { non-frail } \\
56 \text { pre-frail } \\
20 \text { frail } \\
\text { Age }>65\end{array}$ & $\begin{array}{l}\text { Foot problems are } \\
\text { associated with frailty. } \\
\text { Sensor-based gait } \\
\text { parameters can identify } \\
\text { foot problems and older } \\
\text { adults at risk for falls or } \\
\text { gait abnormalities related } \\
\text { to foot problems. }\end{array}$ \\
\hline
\end{tabular}




\begin{tabular}{|c|c|c|c|c|}
\hline $\begin{array}{l}\text { Ozaki et al. (2017), } \\
\text { Japan }\end{array}$ & Cross-over trial & $\begin{array}{l}\text { To examine the efficacy of } \\
\text { postural strategy training using } \\
\text { a balance exercise assist robot } \\
\text { as compared with conventional } \\
\text { balance training for frail older } \\
\text { adults }\end{array}$ & $\begin{array}{l}27 \text { community } \\
\text { dwelling frail or } \\
\text { prefrail older adults } \\
7 \text { men, } 20 \text { women } \\
\text { Age }>65\end{array}$ & $\begin{array}{l}\text { In frail or prefrail older } \\
\text { adults, robotic exercise } \\
\text { was more effective for } \\
\text { improving dynamic } \\
\text { balance and lower } \\
\text { extremity muscle strength } \\
\text { than conventional } \\
\text { exercise. }\end{array}$ \\
\hline $\begin{array}{l}\text { Parvaneh et al. } \\
\text { (2017), USA }\end{array}$ & $\begin{array}{l}\text { Observational } \\
\text { cohort study }\end{array}$ & $\begin{array}{l}\text { To monitor and assess daily } \\
\text { postural transition differences } \\
\text { by frailty level in community } \\
\text { dwelling older adults. }\end{array}$ & $\begin{array}{l}120 \text { community } \\
\text { dwelling older adults } \\
\text { Age }>65 \\
\text { Without gait or } \\
\text { mobility disorders }\end{array}$ & $\begin{array}{l}\text { Monitoring daily physical } \\
\text { activity, specifically } \\
\text { quantification of postural } \\
\text { transitions using inertial } \\
\text { wearable sensors may } \\
\text { provide an objective tool } \\
\text { for assessing frailty during } \\
\text { unsupervised conditions } \\
\text { in home. }\end{array}$ \\
\hline $\begin{array}{l}\text { Peek et al. (2016), The } \\
\text { Netherlands }\end{array}$ & $\begin{array}{l}\text { Qualitative } \\
\text { explorative } \\
\text { field study }\end{array}$ & $\begin{array}{l}\text { To explore which factors influence } \\
\text { the level of use of various types } \\
\text { of technology by older adults who } \\
\text { are aging in place and to describe } \\
\text { these factors in a comprehensive } \\
\text { model }\end{array}$ & $\begin{array}{l}53 \text { community } \\
\text { dwelling older adults } \\
\text { Aged } 68-95\end{array}$ & $\begin{array}{l}\text { Older adults perceptions } \\
\text { and use of technology } \\
\text { are embedded in their } \\
\text { personal, social and } \\
\text { physical context. }\end{array}$ \\
\hline $\begin{array}{l}\text { Rahemi et al. (2018), } \\
\text { USA }\end{array}$ & $\begin{array}{l}\text { Observational } \\
\text { cohort study }\end{array}$ & $\begin{array}{l}\text { To investigate the feasibility of } \\
\text { developing a foot-worn sensor to } \\
\text { assess frailty }\end{array}$ & $\begin{array}{l}161 \text { community } \\
\text { dwelling older adults } \\
\text { Age }>55 \\
\text { Non-frail } 49 \\
\text { Pre-frail } 92 \\
\text { Frail } 20 \\
\end{array}$ & $\begin{array}{l}\text { Foot-worn sensor- } \\
\text { derived gait measures } \\
\text { during propulsive phase } \\
\text { of walking can be } \\
\text { sensitive metrics in frailty } \\
\text { assessment. }\end{array}$ \\
\hline $\begin{array}{l}\text { Razjouyan et al. } \\
\text { (2018), USA }\end{array}$ & $\begin{array}{l}\text { Cross-sectional } \\
\text { study }\end{array}$ & $\begin{array}{l}\text { To determine which sensor- } \\
\text { derived parameters are capable } \\
\text { of discriminating between the } 3 \\
\text { frailty categories. }\end{array}$ & $\begin{array}{l}153 \text { community } \\
\text { dwelling older adults } \\
\text { Age }>60 \\
\text { Able to walk } 15 \text { feet } \\
\text { independently with or } \\
\text { without aid }\end{array}$ & $\begin{array}{l}\text { A pendant sensor can } \\
\text { identify pre-frailty via } \\
\text { daily home monitoring. }\end{array}$ \\
\hline $\begin{array}{l}\text { Rye Hanton et al. } \\
\text { (2017), USA }\end{array}$ & $\begin{array}{l}\text { Observational } \\
\text { cohort study }\end{array}$ & $\begin{array}{l}\text { To demonstrate data derived } \\
\text { from ubiquitous mobile phone } \\
\text { technology can be employed to } \\
\text { continuously measure aspects of } \\
\text { participant health status, including } \\
\text { step counts, gait speed and activity } \\
\text { level. }\end{array}$ & $\begin{array}{l}43 \text { ambulatory, } \\
\text { community dwelling } \\
\text { older adults } \\
25 \text { robust } \\
18 \text { frail }\end{array}$ & $\begin{array}{l}\text { Continuous mobile } \\
\text { phone-based measures } \\
\text { of activity and mobility } \\
\text { can differentiate between } \\
\text { frailty and non-frail older } \\
\text { adults. }\end{array}$ \\
\hline $\begin{array}{l}\text { Schwenk et al. (2015), } \\
\text { USA }\end{array}$ & $\begin{array}{l}\text { Observational, } \\
\text { cross-sectional } \\
\text { study }\end{array}$ & $\begin{array}{l}\text { To examine the ability of wearable } \\
\text { sensor-based in-home assessment } \\
\text { of gait, balance, and physical } \\
\text { activity to discriminate between } \\
\text { frailty levels. }\end{array}$ & $\begin{array}{l}125 \text { older adults } \\
44 \text { non-frail } \\
60 \text { pre-frail } \\
21 \text { frail }\end{array}$ & $\begin{array}{l}\text { Unique parameters } \\
\text { derived from objective } \\
\text { assessment of gait, } \\
\text { balance, and physical } \\
\text { activity are sensitive for } \\
\text { the identification of pre- } \\
\text { frailty and classification } \\
\text { of a subjects' frailty level. }\end{array}$ \\
\hline
\end{tabular}




\begin{tabular}{|l|l|l|l|l|}
\hline $\begin{array}{l}\text { Toosizadeh et al. } \\
\text { (2015), USA }\end{array}$ & $\begin{array}{l}\text { Cross sectional } \\
\text { study }\end{array}$ & $\begin{array}{l}\text { To objectively identify frailty } \\
\text { using wireless sensors and } \\
\text { an upper extremity motion } \\
\text { assessment that does not rely on } \\
\text { gait. }\end{array}$ & $\begin{array}{l}117 \text { community } \\
\text { dwelling older adults } \\
50 \text { nonfrail }\end{array}$ & $\begin{array}{l}\text { This upper extremity } \\
\text { frailty assessment method } \\
\text { integrates low cost sensors } \\
\text { and implemented in less } \\
\text { than } 1 \text { minute objectively } \\
\text { identifies frailty. }\end{array}$ \\
\hline
\end{tabular}

\section{References}

Apostolo, J., Cooke, R., Bobrowicz-Campos, E., Santana, S., Marcucci, M., Cano, A., Vollenbroek-Hutten, M., Germini, F., D'Avanzo, B., Gwyther, H., \& Holland, C. (2018). Effectiveness of interventions to prevent pre-frailty and frailty progression in older adults: A systematic review. JBI Database of Systematic Reviews and Implementation Reports, 16(1). http://dx.doi.org/10.11124/JBISRIR-2017-003382

Buckinx, F., Rolland, Y., Reginster, J., Ricour, C., Petermans, J., \& Bruyere, O. (2015). Burden of frailty in the elderly population: Perspectives for a public health challenge. Archives of Public Health, 73(1). http://dx.doi.org/10.1186/s13690-015-0068-x

Chang, S. \& Lin,P. (2015). Frail phenotype and mortality prediction: A systematic review and meta-analysis of prospective cohort studies. International Journal of Nursing Studies, 52, 13621374. http://dx.doi.org/10.1016/j.ijnurstu.2015.04.005

Clegg, A., Young, J., Iliffe, S., Rikkert, M.O., \& Rockwood, K. (2013). Frailty in elderly people. Lancet, 381(9868), 752-762. http://dx.doi.org/10.1016/S0140-6736(12)62167-9

Collard, R.M., Boter, H., Schoevers, R., \& Voshaar, R.C. (2012). Prevalence of frailty in community dwelling older persons: A systematic review. JAGS, 60, 1487-1492. http://dx.doi. org/10.1111/j.1532-5415.2012.04054.x

Conroy, S. \& Elliot, A. (2016). The frailty syndrome. Medicine, 45(1), 15-18. http://dx.doi.org/10.1016/j.mpmed.2016.10.010

Dekker-van Weering, M., Jansen-Kosterink, S., Frazer, S., \& Vollenbroek-Hutten, M. (2017). User experience, actual use, and effectiveness of an information and communication technology-supported home exercise program for pre-frail older adults. Frontiers in Medicine, 4(208). http://dx.doi. org/10.3389/fmed.2017.00208

De Labra, C., Guimaraes-Pinheiro, C., Maseda, A., Lorenzo, T., \& Millan-Calenti, J.C. (2015). Effects of physical exercise interventions in frail older adults: A systematic review of randomized controlled trials. BMC Geriatrics, 15(154). http:// dx.doi.org/10.1186/s12877-015-0155-4

De Vries, N.M., van Ravensberg, C.D., Hobbelen, J.S.M., Olde Rikkert, M.G.M., Staal, J.B., \& Nijhuis-van der Sanden, M.W.G. (2012). Effects of physical exercise therapy on mobility, physical functioning, physical activity and quality of life in community-dwelling older adults with impaired mobility, physical disability, and/or multi-morbidity: A metaanalysis. Aging Research Reviews, 11, 136-149. http://dx.doi. org/10.1016/j.arr.2011.11.002

Feng, Z., Lugtenberg, M., Franse, C., Fang, X., Hu, S., Jin, C., \& Raat, H. (2017). Risk factors and protective factors associated with incident or increase of frailty among community-dwelling older adults: A systematic review of longitudinal studies. PLoS One, 12(6). http://dx.doi.org/10.1371/journal.pone.0178383
Fried, L.P., Tangen, C.M., Walston, J., Newman, A.B., Hirsch, C., Gottdiener, J., Seeman, T., Russell, T., Kop, W.J., Burke, G., \& McBurnie, M.A. (2001). Frailty in older adults: Evidence for a phenotype. Journal of Gerontology, 56A(3), M146-M156. http://dx.doi.org/10.1093/gerona/56.3.m146

Galan-Mercant, A. \& Cuesta-Vargas, A.I. (2013). Differences in trunk accelerometry between frail and nonfrail elderly persons in sit-to-stand and stand-to-sit transitions based on a mobile inertial sensor. JMIR Mhealth Uhealth, I(2), e21. http://dx.doi. org/10.2196/mhealth.2710

Galan-Mercant, A. \& Cuesta-Vargas, A.I. (2014). Differences in trunk accelerometry between frail and non-frail elderly persons in functional tasks. BMC Research Notes, 7(100). http://dx.doi. org/10.1186/1756-0500-7-100

Galan-Mercant, A. \& Cuesta-Vargas, A.I. (2015). Clinical frailty syndrome assessment using inertial sensors embedded in smartphones. Physiologic Measurement, 36, 1929-1942. http:// dx.doi.org/10.1088/0967-3334369/1929

Geraedts, H.A.E., Zijlstra, W., Zhang, W., Spoorenberg, S.L.W., Baez, M., Khaghani, I., Baldus, H., \& Stevens, M. (2017). A home-based exercise program driven by tablet application and mobility monitoring for frail older adults: Feasibility and practical implications. Preventing Chronic Disease, 14(12). http://dx.doi.org/10.5888/pcd14.160227

Greene, B.R., Doheny, E.P., Kenny, R.A., \& Caulfield, B. (2014a). Classification of frailty and falls history using a combination of sensor-based mobility assessments. Physiological Measurement, 35, 2053-2066. http://dx.doi.org/10.1088/0967$3334 / 35 / 10 / 2053$

Greene, B.R., Doheny, E.P., O'Halloran, A., \& Kenny, R.A. (2014b). Frailty status can be accurately assessed using inertial sensors and the TUG test. Age and Ageing, 43, 406-411. http:// dx.doi.org/10.1093/ageing/aft176

Inouye, S.K., Studenski, S., Tinetti, M.E., \& Kuchel, G.A. (2007). Geriatric syndromes: Clinical, research and policy implications of a core geriatric concept. JAGS, 55(5), 780-791. http://dx.doi. org/10.1111/j.1532-5415.2007.01156.x

Kane, R.L., Shamliyan, T., Talley, K., \& Pacala, J. (2012). The association between geriatric syndromes and survival. JAGS, 60(3), 896-904. http://dx.doi.org/10.1111/j.15325415.2012.03942.x

Kojima, G. (2017). Frailty as a predictor of disabilities among community-dwelling older people: A systematic review and meta-analysis. Disability and Rehabilitation, 39(19). http:// dx.doi.org/10.1080/09638288.2016.1212282

Kojima, G. (2018). Frailty defined by FRAIL scale as a predictor of mortality: A systematic review and meta-analysis. JAMDA, 19, 480-483. http://dx.doi.org/10.1016/j.jamda.2018.04.006 
Martinez-Ramirez, A., Martinikorena, I., Gomez, M., Lecumberri, P., Millor, N., Rodriguez-Manas, L., Garcia, F.J., \& Izquierdo, M. (2015). Frailty assessment based on trunk kinematic parameters during walking. Journal of Neuroengineering and Rehabilitation. http://dx.doi.org/10.1186/s12984-015-0040-6

Mohler, J.M., Wendel, C.S., Taylor-Piliae, R.E., Toosizadeh, N., \& Najafi, B. (2016). Motor performance and physical activity as predictors of prospective falls in communitydwelling older adults by frailty level: Application of wearable technology. Gerontology, 62, 654-664. http://dx.doi. org/10.1159/000445889

Muchna, A., Najafi, B., Wendel, C.S., Schwenk, M., Armstrong, D.G., \& Mohler, J. (2018). Foot problems in older adults. Journal of the American Podiatric Medical Association, 108(2). http://dx.doi.org/10.7547/15-186

Ozaki, K., Kondo, I., Hirano, S., Kagaya, H., Saitoh, E., Osawa, A., \& Fujinori, Y. (2017). Training with a balance exercise assist robot is more effective than conventional training for frail older adults. Geriatrics and Gerontology International, 17, 1982-1990. http://dx.doi.org/10.1111/ggi.13009

Parvaneh, S., Mohler, J., Toosizadeh, N., Grewal, G.S., \& Najafi, B. (2017). Postural transitions during activities of daily living could identify frailty status: Application of wearable technology to identify frailty during unsupervised condition. Gerontology, 63, 479-487. http://dx.doi.org/10.1159/000460292

Peek, S.T., Luijkx, K.G., Rijnaard, M.D., Nieboer, M.E., van der Voort, C.S., Aarts, S., van Hoof, J., Vrijhoef, H.J.M., \& Wouters, E.J.M. (2016). Older adults' reasons for using technology while aging in place. Gerontology, 62, 226-237. http://dx.doi.org/10.1159/000430949

Pilotto, A., Boi, R., \& Petermans, J. (2018). Technology in geriatrics. Age and Ageing, 0, 1-4. http://dx.doi.org/10.1093/ ageing/afy026

Provencher, V., Beland, F., Demers, L., Desrosiers, J., Bier, N., Avila-Funes, J.A., Galand, C., Julien, D., Fletcher, J.D., Trottier, L., \& Hami, B. (2017). Are frailty components associated with disability in specific activities of daily living in community-dwelling older adults? A multicenter Canadian study. Archives of Gerontology and Geriatrics, 73, 187-194. http://dx.doi.org/10.1016/j.archger.2017.07.027

Puts, M.T.E., Toubasi, S., Andrew, M.K., Ashe, M.C., Ploeg, J., Atkinson, E., Ayala, A.P., Roy, A., Monforte, M.R., Bergman, H., \& McGilton, K. (2017). Interventions to prevent or reduce the level of frailty in community-dwelling older adults: a scoping review of the literature and international policies. Age and Ageing, 46, 383-392. http://dx.doi.org/10.1093/ageing/afw247

Rahemi, H., Nguyen, H., Lee, H., \& Najafi, B. (2018). Toward smart footwear to track frailty phenotypes using propulsion performance to determine frailty. Sensors, 18(1763). http:// dx.doi.org/10.3390/s18061763

Razjouyan, J., Naik, A.D., Horstman, M.J., Kunik, M.E., Amirmazaheri, M., Zhou, H., Sharafkhaneh, A., \& Najafi, B. (2018). Wearable sensors and the assessment of frailty among vulnerable older adults: An observational cohort study. Sensors, 18(1336). http://dx.doi.org/10.3390/s18051336

Robertson, D.A., Savva, G.M., \& Kenny, R.A. (2013). Frailty and cognitive impairment - a review of the evidence and causal mechanisms. Ageing Research Reviews, 12, 840-851. http:// dx.doi.org/10.1016/j.arr.2013.06.004

Rockwood, K. \& Mitnitski, A. (2011). Frailty defined by deficit accumulation and geriatric medicine defined by frailty. Clinical Geriatric Medicine, 27, 17-26. http://dx.doi.org/10.1016/j. cger.2010.08.008

Rye-Hanton, C., Kwon, Y., Aung, T., Whittington, J., High, R.R., Goulding, E.H., Schenk, A.K., \& Bonasera, S.J. (2017). Mobile phone-based measures of activity, step count, and gait speed: Results from a study of ambulatory adults in a naturalistic setting. JMIR Mhealth Uhealth, 5(10), e104. http://dx.doi. org/10.2196/mhealth.5090

Schwenk, M., Mohler, J., Wendel, C., D'Huyvetter, K., Fain, M., Taylor-Piliae, R., \& Najafi, B. (2015). Wearable sensor-based in-home assessment of gait, balance and physical activity for discrimination of frailty status: Baseline results of the Arizona Frailty Cohort Study. Gerontology, 61, 258-267. http://dx.doi. org/10.1159/000369095

Silva, R., Pizato, N., Da Mata, F., Figueiredo, A., Ito, M., \& Pereira, M.G. (2018). Mediterranean diet and musculoskeletal functional outcomes in community-dwelling older people: A systematic review and meta-analysis. Journal of Nutrition Health and Aging, 22(6), 655-663. http://dx.doi.org/10.1017/ s12603-017-0993-1

Siriwardhana, D.D., Hardoon, S., Rait, G., Weerasinghe, M.C., \& Walters, K.R. (2018). Prevalence of frailty and prefrailty among community-dwelling older adults in low-income and middle-income countries: A systematic review and metaanalysis. BMJ Open, 8, e018195. http://dx.doi.org/10.1136/ bmjopen-2017-018195

Theou, O., Stathokostas, L., Roland, K.P., Jakobi, J.M., Patterson, C., Vandervoort, A.A., \& Jones, G.R. (2011). The effectiveness of exercise interventions for the management of frailty: A systematic review. Journal of Aging Research. http://dx.doi. org/10.4061/2011/569194

Toosizadeh, N., Mohler, J., \& Najafi, B. (2015). Assessing upper extremity motion: An innovative method to identify frailty. JAGS, 63, 1181-1186. http://dx.doi.org/10.1111/jgs.13451

Tricco, A.C., Lillie, E., Zarin, W., O’Brien, K.K., Colquhoun, H., Levac, D., Moher, D., Peters, M.D.J., Horsley, T., Weeks, L., Hempel, S., Akl, E.A., Chang, C., McGowan, J., Stewart, L., Hartling, L., Aldcroft, A., Wilson, M.G., Garritty, C., ... Straus, S.E. (2018). PRISMA extension for scoping reviews (PRISMA-ScR): Checklist and explanation. Annals of Internal medicine, 169, 467-473. http://dx.doi.org/10.7326/M18-0850

Xue, Q. (2011). The frailty syndrome: Definition and natural history. Clinical Geriatric Medicine 27, 1-15. http://dx.doi. org/10.1016/j.cger.2010.08.009 